OAK RIDGE

NATIONAL LABORATORY MANAGED BY UT-BATTELLE FOR THE DEPARTMENT OF ENERGY
Mechanical Response of Stitched T300 Mat/Urethane 420 IMR Composite Laminates: Property/Orientation Dependence and Damage Evolution

S. Deng

Y. J. Weitsman 



\title{
MECHANICAL RESPONSE OF STITCHED T300 MAT/URETHANE 420 IMR COMPOSITE LAMINATES: PROPERTY/ORIENTATION DEPENDENCE AND DAMAGE EVOLUTION
}

\author{
S. Deng \\ Y. J. Weitsman
}

March 2000

Prepared by the OAK RIDGE NATIONAL LABORATORY

Oak Ridge, Tennessee 37831-6285

managed by

UT-BATTELLE, LLC, for the

U.S. DEPARTMENT OF ENERGY under contract DE-AC05-00OR22725 



\section{CONTENTS}

ABSTRACT

1

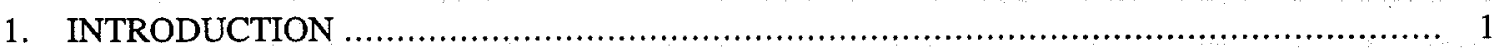

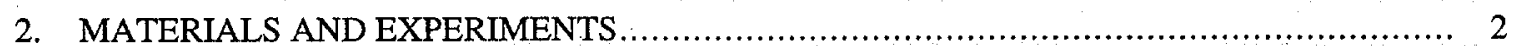

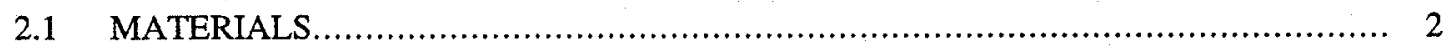

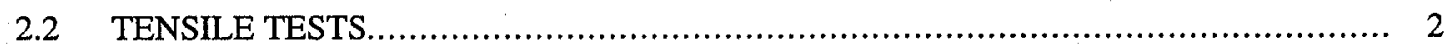

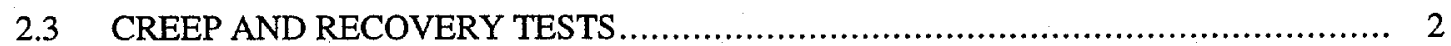

2.4 INTERNAL DAMAGE DETECTION ......................................................... 3

3. ANALYTICAL PREDICTION OF LAMINATE MECHANICAL RESPONSE.................... 3

3.1 PREDICTION OF TENSILE MODULUS OF CROSS-PLY LAMINATES .................. 3

3.2 ESTIMATION OF DISCREPANCY IN TENSILE PROPERTIES CAUSED BY LAY-UP MISORIENTATIONS FOR QUASI-ISOTROPIC LAMINATES................... 4

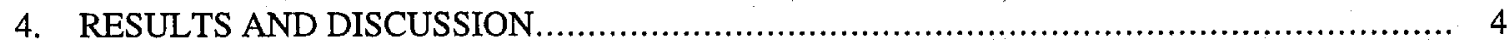

4.1 TENSILE PROPERTIES OF CROSS-PLY LAMINATES ................................... 4

4.2 EFFECT OF SPECIMEN SIZE ON OFF-AXIL TENSILE PROPERTIES OF CROSS-PLY LAMINATES ................................................................... 5

4.3 TENSILE PROPERTIES OF [0/90/45/-45] S (QUASI-ISOTROPIC) LAMINATES .......... 7

4.4 COMPARISON OF TENSILE PROPERTIES OF THREE LAMINATES WITH

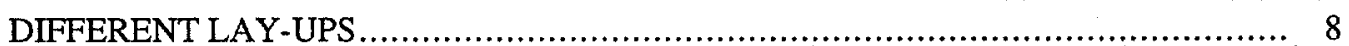

4.5 INTERNAL DAMAGE DEVELOPMENT UNDER EXTERAL LOADING .................. 8

4.6 CREEP AND RECOVERY BEHAVIOR OF CROSS-PLY LAMINATE COUPONS ....... 9

4.6.1 Influcnec of Crecp Stress Levels.......................................................... 9

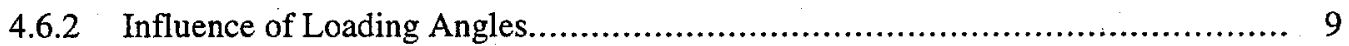

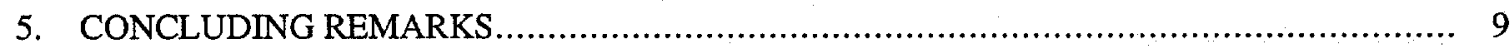

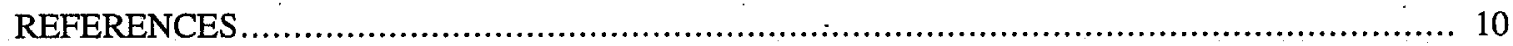





\section{LIST OF FIGURES}

Figure

1. Schematic drawings of cross-ply stitched T300 mat/urethane 420 IMR laminates with two lay-up sequences

2. Schematic drawing of $[0 / 90 / 45 /-45]_{3 S}$ quasi-isotopic T300 stitched mat/urethane $420 \mathrm{IMR}$ laminate .

3. Illustration of a test coupon for tensile and creep and recovery tests

4. Illustration of quasi-isotropic laminate with lay-up misalignment

5. Typical stress-strain curves of $[45 /-45]_{6}$ stitched T300 mat/urethane $420 \mathrm{IMR}$ composites.......... 14

6. Typical stress-strain curves of $[45 /-45]_{3 \mathrm{~S}}$ stitched T300 mat/urethane $420 \mathrm{IMR}$ composites......... 15

7. Strength vs loading angle $[45 /-45]_{6}$ and $[45 /-45]_{3 \mathrm{~S}}$ stitched T300 mat/urethane $420 \mathrm{IMR}$ composites.

8. Stiffness vs loading angle of $[45 /-45]_{6}$ and $[45 /-45]_{3 \mathrm{~S}}$ stitched T300 mat/urethane $420 \mathrm{IMR}$ composites.

9. Failure strain vs loading angle of $[45 /-45]_{6}$ and $[45 /-45]_{3 \mathrm{~S}}$ stitched T300 mat/urethane $420 \mathrm{IMR}$ composites.

10. Variations in tensile stiffness vs loading orientation for $[45 /-45]_{6}$ and $[45 /-45]_{3 S}$ composite laminates and comparison with predictions of classical laminate theory

11. Tensile results of test coupons with two different widths, showing the influence of specimen size on the strength of $\left[ \pm 45^{\circ}\right]_{3 S}$ laminates.

12. Schematic drawings of test coupons with two different widths, showing larger proportion of unconstrained fibers in the narrower specimen

13. Typical stress-strain curves of [0/90/45/-45] suasi-isotropic stitched T300 mat/urethane $420 \mathrm{IMR}$ composites at various orientations

14. Stiffness vs orientation angle of $[0 / 90 / 45 /-45]_{\mathrm{s}}$ quasi-isotropic stitched $\mathrm{T} 300$ mat/urethane 420 IMR composites. (The values for ideal quasi-isotropic laminates are calculated using laminate theory.)

15. Influence of laminate lay-up misalignment stiffness of [0/90/45/-45] $]_{s}$ quasi-isotropic stitched T300 mat/urethane 420 IMR composites.

16. Comparison of failure strains of stitched T300 mat/urethane 420 IMR composites with different laminate layups.

17. Comparison of tensile strengths of stitched T300 mat/urethane $420 \mathrm{IMR}$ composites with different laminate lay-ups.

18. Comparison of linear-elastic tensile moduli of stitched T300 mat/urethane $420 \mathrm{IMR}$ composites with different laminate lay-ups

19. Stress-strain curves of [45/-45 $]_{3 S}$ laminated coupon, at loading angle $\phi=45^{\circ}$, subjected to progressively stepped-up load levels.

20. (a) X-ray images showing damage in $[45 /-45]_{3 \mathrm{~S}}$ stitched T300 mat/urethane 420 IMR composite $\left(\phi=45^{\circ}\right)$ at various stress levels in \% UTS)

20. (b) X-ray images showing damage in $[45 /-45]_{3 S}$ stitched T300 mat/urethane 420 IMR composite $\left(\phi=45^{\circ}\right)$ at various stress levels (in $\%$ UTS).

21. Loading-unloading curves of a typical in [45/-45] 3 laminate coupon with $\phi=45^{\circ}$ showing the evolution of internal damage with increasing stress levels

22. Stiffness reduction of $[45 /-45]_{3 \mathrm{~S}}$ laminate coupons $\left(\phi=45^{\circ}\right)$, as recorded within the linear range, reloading due to prior tensile loading

23. X-ray images of a [45/-45] 3 stitched T300 mat/urethane $420 \mathrm{IMR}$ coupon $\left(\phi=15^{\circ}\right)$ subjected to various stress levels (in \% UTS). No extensive damage can be detected prior to final failure ... 33 
24. Loading-unloading stress-strain curves of a quasi-isotropic coupon with different stress levels at a loading direction $\phi=45^{\circ}$ (specimen TJB59-45-1)

25. X-ray images of a quasi-isotropic coupon subjected to various stress levels (in \% UTS) at a loading angle $\phi=45^{\circ}$. No extensive damage could be detected until the advent of final failure (specimen TJB59-45-1)

26. Typical creep and recovery curves of $[45 /-45]_{3 \mathrm{~S}}$ laminate coupons $\left(\phi=45^{\circ}\right)$ at $23^{\circ} \mathrm{C}$ under various stress levels.

27. X-ray images showing damage after creep loading in $[45 /-45]_{3 \mathrm{~S}}$ stitched $\mathrm{T} 300$ mat/urethane 420 IMR composite $\left(\phi=30^{\circ}\right)$ at various stress levels (in \% UTS).

28. Typical creep and recovery curves of $[45 /-45]_{35}$ laminate coupons $\left(\phi=0^{\circ}, 15^{\circ}, 30^{\circ}, 45^{\circ}\right)$ at $23^{\circ} \mathrm{C}$ under an applied creep stress $\sigma=60 \%$ UTS. 


\section{LIST OF TABLES}

1. Material parameters used for estimating basic properties of an individual lamina within stitched T300 mat/urethane 420 IMR cross ply coupons.

2. Tensile data for $[45 /-45]_{6}$ (antisymmetric) T300 stitched mat/urethane 420 IMR laminate coupons.

3. Tensile data for $[45 /-45]_{3 \mathrm{~S}}$ (symmetric) $\mathrm{T} 300$ stitched mat/urethane 420 IMR laminate coupons loaded at various orientations

. Comparison of tensile data for [45/-45] $]_{3 S}$ (symmetric) T300 stitched mat/urethane $420 \mathrm{IMR}$ laminate coupons with two specimen widths $\left(\phi=45^{\circ}\right)$

5. Tensile data for $[0 / 90 / 45 /-45]_{s}$ (quasi-isotropic) $\mathrm{T} 300$ stitched mat/urethane $420 \mathrm{IMR}$ laminate coupons loaded at various orientations 


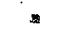




\title{
MECHANICAL RESPONSE OF STITCHED T300 MAT/URETHANE 420 IMR COMPOSITE LAMINATES: PROPERTY/ORIENTATION DEPENDENCE AND DAMAGE EVOLUTION
}

\author{
S. Deng* and Y. J. Weitsman*
}

\begin{abstract}
This report presents experimental and analytical results of investigations on the mechanical response of stitched T300 mat/urethane 420 IMR composite laminates with three different lay-up configurations. Tensile tests and short-term creep and recovery tests were conducted on the laminate coupons at various orientations. The $\mathrm{X}$-ray photographic technique was adopted to detect the internal damage due to external loading history. The tensile data of laminates with antisymmetric and symmetric lay-ups indicated that layup sequences of cross-ply laminates do not have much influence on their tensile properties. However, misalignments within the stitch-bonded plies disturb the symmetry of intended quasi-isotropic laminates and thereby cause the mechanical properties to exhibit a certain amount of angular dependence. Classic lamination theory was found to be able to provide a very good prediction of tensile properties for the stitched laminates within linear range. Creep and recovery response of laminate coupons is greatly dependent on loading angles and load levels. The internal damage of laminate coupons is also directly related to loading angles and load levels as well as loading history.
\end{abstract}

\section{INTRODUCTION}

In the ongoing Automotive Composite Consortium (ACC)/Oak Ridge National Laboratory (ORNL) project "Durability of Carbon-Fiber Composites," stitched T300 mat/urethane 420 IMR composites are being explored as a potential class of materials for application in the automotive industry. The stitched T300 mat was made by stitching cross-ply dry preforms, consisting of layers reinforced by T300 graphite fibers, at a stitch angle of $45^{\circ}$ about the longitudinal fiber direction and with spacings of $5 \mathrm{~mm}$, as well as $3 \mathrm{~mm}$. By assembling the above pairs of stitched plies and injecting them with urethane $420 \mathrm{IMR}$, the composite laminates were thus fabricated with several lay-up sequences. ${ }^{\dagger}$ As a result of anisotropy (orthotropy), the mechanical responses of the finished laminates under various loading conditions may vary with load directions. Similarly, the internal damage induced by external loading is also likely dependent on loading directions and load levels.

This report presents the experimental data obtained from stitched T300 mat/urethane 420 IMR composite laminates with three different lay-ups. These experiments include tensile tests, short-term creep and recovery tests at various orientations, and damage detection within the test coupons by means of X-ray photography. An analytical approach based on classical laminate theory is employed to predict the stiffness of the three laminates with regard to various loading orientations.

\footnotetext{
* MAES Department, University of Tennessee, Knoxville, TN 37996-2030 and Engineering Technology Division, Oak Ridge National Laboratory, M/S 8051, Oak Ridge, TN 37830-8051.

${ }^{\dagger}$ A detailed description of the materials and their processing procedures can be found in Ref. [1].
} 


\section{MATERIALS AND EXPERIMENTS}

\subsection{MATERIALS}

Three types of T300 stitched mat/urethane 420 IMR laminate plaques with [45/-45] (antisymmetric), [45/-45] $]_{3 S}$ (symmetric), and [0/90/45/-45] (quasi-isotropic) lay-ups were provided by ACC. A single [45/-45] $]_{6}$ plaque (C7, by ORNL designation, with stitch spacing of $3 \mathrm{~mm}$ ), measuring $\sim 3$ $\mathrm{mm}$ in thickness, was used in this study. This plaque has 12 layers of T300 stitched mats with the lay-up sequence shown in Fig. 1(a), and its fiber volume fraction is $41.5 \%$ according to ACC. Four $[45 /-45]_{3 \mathrm{~S}}$ plaques [C49, C53, C54 and C55 (ORNL) all with stitch spacings of $5 \mathrm{~mm}$ ] with an average thickness of $\sim 3 \mathrm{~mm}$ were subsequently tested. Each of these plaques also has 12 layers of T300 stitched mats with symmetric lay-ups, shown in Fig. 1(b). The fiber volume fractions for these plaques were $45.7 \%, 38.9 \%$, $38.9 \%$ and $37.6 \%$, respectively. Data for a quasi-isotropic lay-up were collected for the $[0 / 90 / 45 /-45]_{s}$ plaque (TJB59) with eight layers of T300 stitched mats, shown in Fig. 2. This plaque had an average thickness of $2.0 \sim 2.2 \mathrm{~mm}$. All the plaques were square, measuring 24 in. by $24 \mathrm{in} .(609.6 \times 609.6 \mathrm{~mm})$.

\subsection{TENSILE TESTS}

Test coupons measuring $203.2 \mathrm{~mm}$ long and $25.4 \mathrm{~mm}$ wide $(8 \times 1 \mathrm{in}$.) wcre cut from the above plaques with different angles, $\phi$, relative to the fiber longitudinal direction in the top ply, as shown in Figs. 1 and 2. Cross-ply glass fiber laminates with a thickness of $1.6 \mathrm{~mm}$ were adopted as tabs, which were glued on the two ends of test coupons using high-strength epoxy to prevent the possible damage caused by the grips of the testing machine. A finished test coupon prior to testing is illustrated in Fig. 3.

Tensile tests were conducted using an 810 MTS Material Testing System with a loading rate of $1.016 \mathrm{~mm} / \mathrm{min}(0.04 \mathrm{in} . / \mathrm{min})$ at room temperature $\left(23^{\circ} \mathrm{C}\right)$. An extensometer and strain gages were used for recording the strain data in both the longitudinal and transverse directions of the test coupons.

To study the influence of specimen size on the off-axial tensile properties of cross-ply laminates, six 2-in.-wide test coupons $\left(\phi=45^{\circ}\right)$, cut from laminate panels with symmetric lay-ups, were tested at the same condition as their 1-in.-wide counterparts to compare their tensile properties.

\subsection{CREEP AND RECOVERY TESTS}

These same tensile coupons were adopted for creep and recovery tests. The short-term creep and recovery tests were performed on the 810 MTS Material Testing System with a load control mode at various levels of fixed stresses. An MTS extensometer and strain gages were utilized to record the deformation response during creep loading followed by recovery on unloading. The forcgoing tests involved $5 \mathrm{~h}$ of creep followed by $15 \mathrm{~h}$ of strain recovery. All the tests were performed at room temperature $\left(23^{\circ} \mathrm{C}\right)$. The average creep rate was defined as the total strain increment divided by the corresponding increment of time, and the residual strain values at the end of the recovery period were considered to be permanent strains.

\subsection{INTERNAL DAMAGE DETECTION}

An X-ray photography technique was used to detect internal damage induced by stepwise load increments. Liquid penetrant (zinc iodide solution) was applied at various stages of loading, as well as after 
the test was completed. Coupons were immersed in the penetrant solution for several hours to enhance the resolution of the X-ray images. X-ray exposure was conducted in an HP 43804N X-ray machine at $30 \mathrm{kvp}$ for 1.5 min using Polaroid films. Progressive increments in load levels, in percentage of ultimate tensile strength (\%UTS), were applied to the test coupons to capture the sequence of damage development. X-ray photographs were taken at each intermittent stage of load removal.

\section{ANALYTICAL PREDICTION OF LAMINATE MECHANICAL RESPONSE}

\subsection{PREDICTION OF TENSILE MODULUS OF CROSS-PLY LAMINATES}

According to classical laminate theory ${ }^{2}$, the laminate force per unit length $\left(N_{i}\right)$ is expressed as:

$$
\left\{\begin{array}{l}
N_{x}=A_{11} \varepsilon_{x}+A_{12} \varepsilon_{y}+A_{16} \gamma_{x y} \\
N_{y}=A_{12} \varepsilon_{x}+A_{22} \varepsilon_{y}+A_{26} \gamma_{x y} \\
N_{x y}=A_{16} \varepsilon_{x}+A_{26} \varepsilon_{y}+A_{66} \gamma_{x y}
\end{array}\right.
$$

where $A_{i j}$ are the laminate stiffnesses, and $\varepsilon$ and $\gamma$ denote normal and shear strains.

For a uniaxial loading in the $\mathrm{X}$-direction (i.e., longitudinal direction of test coupons, as shown in Figs. 1 and 2), the above equations give

$$
\left\{\begin{array}{l}
A_{11} \varepsilon_{x}+A_{12} \varepsilon_{y}+A_{16} \gamma_{x y}=N_{x} \\
A_{12} \varepsilon_{x}+A_{22} \varepsilon_{y}+A_{26} \gamma_{x y}=0 \\
A_{16} \varepsilon_{x}+A_{26} \varepsilon_{y}+A_{66} \gamma_{x y}=0
\end{array}\right.
$$

Therefore, the longitudinal modulus of a test coupon under uniaxial tension can be reduced to read:

$$
E_{x}=\frac{1}{n_{p} h_{o}}\left(\frac{N_{x}}{\varepsilon_{x}}\right)=\frac{1}{n_{p} h_{o}}\left(A_{11}-\frac{A_{12}^{2} A_{66}+A_{66} A_{16}^{2}-2 A_{12} A_{16} A_{26}}{A_{22} A_{66}-A_{26}^{2}}\right),
$$

where $h_{o}$ is the thickness of a lamina and $n_{p}$ is the total number of plies. The laminate stiffnesses $A_{i j}$ are related to the ply stiffnesses $Q_{11}, Q_{22}, Q_{12}$ and $Q_{66}$, which were determined previously ${ }^{3}$ and are listed in Table 1 below:

Table 1. Material parameters used for estimating basic properties of an individual lamina within stitched T300 mat/urethane $420 \mathrm{IMR}$ cross ply coupons

\begin{tabular}{ccccc}
\hline $\begin{array}{c}h_{o} \\
(\mathrm{~mm})\end{array}$ & $\begin{array}{c}Q_{11} \\
(\mathrm{GPa})\end{array}$ & $\begin{array}{c}Q_{22} \\
(\mathrm{GPa})\end{array}$ & $\begin{array}{c}\mathrm{Q}_{12} \\
(\mathrm{GPa})\end{array}$ & $\begin{array}{c}Q_{66} \\
(\mathrm{GPa})\end{array}$ \\
\hline 0.25 & 88.97 & 0.72 & 3.10 & 3.30 \\
\hline
\end{tabular}

For cross-ply laminates the relations between $A_{i j}$ and $Q_{i j}$ are as follows : ${ }^{2}$ 


$$
\begin{aligned}
& \mathrm{A}_{11}=\mathrm{A}_{22}=6 \mathrm{~h}_{\mathrm{o}}\left[\left(m^{4}+n^{4}\right)\left(Q_{11}+Q_{22}+4 m^{2} n^{2}\right)\left(Q_{12}+2 Q_{66}\right)\right] \\
& A_{12}=6 h_{o}\left[2 m^{2} n^{2}\left(Q_{11}+Q_{22}\right)+2\left(m^{4}+n^{4}\right) Q_{12}-8 m^{2} n^{2} Q_{66}\right] \\
& A_{16}=-A_{26}=6 h_{o}\left[\left(m^{3} n-m n^{3}\right)\left(Q_{11}+Q_{22}\right)+2\left(m n^{3}-m^{3} n\right)\left(Q_{12}+2 Q_{66}\right)\right] \\
& A_{66}=6 h_{o}\left[2 m^{2} n^{2}\left(Q_{11}+Q_{22}\right)-4 m^{2} n^{2} Q_{12}+2\left(m^{2}-n^{2}\right) Q_{66}\right]
\end{aligned}
$$

In this series of equations (4), $m=\cos (\phi)$ and $n=\sin (\phi)$, where $\phi$ denotes the angle between the directions $\mathrm{X}$ and $\mathrm{X}_{1}$, shown in Fig. 1. The value of the ply thickness $h_{o}$ is also listed in Table 1 .

\subsection{ESTIMATION OF DISCREPANCY IN TENSILE PROPERTIES CAUSED BY LAY-UP MISORIENTATIONS FOR QUASI-ISOTROPIC LAMINATES}

A major characteristic of quasi-isotropic lay-ups is that their in-plane stiffnesses do not depend on orientation. Nevertheless, such angular dependence was noted experimentally in the nominally quasiisotropic plaques tested here. To trace the cause for the discrepancy, consider the circumstance where the inner $\left[ \pm 45^{\circ}\right]$ ply groups were tilted by an angle $\alpha$ about their proper directions during the manufacturing process as shown in Fig. 4. Straightforward manipulations of laminate equations yield the following expressions (where $\alpha=0$ stands for perfect quasi-isotropic lay-up):

$$
\begin{aligned}
& A_{11}=A_{22}=\frac{1}{2 h_{o}}\left(Q_{11}+Q_{22}\right)\left\{\cos ^{4} \phi+\sin ^{4} \phi+\frac{1}{2}+\frac{1}{2} \sin ^{2}[2(\alpha+\phi)]\right\}+ \\
& +\frac{1}{2 h_{o}}\left(Q_{12}+2 Q_{66}\right)\left\{\sin ^{2}(2 \phi)+\cos ^{2}[2(a+\phi)]\right\} \\
& A_{12}=\frac{1}{4 h_{o}}\left(Q_{11}+Q_{22}-4 Q_{66}\right)\left\{\sin ^{2}(2 \phi)+\cos ^{2}[2(\alpha+\phi)]\right\}+ \\
& +\frac{1}{h_{o}} Q_{12}\left\{\cos ^{4} \phi+\sin ^{4} \phi+\frac{1}{2}+\frac{1}{2} \sin ^{2}[2(\alpha+\phi)]\right\} \\
& A_{16}=-A_{26}=\frac{1}{8 h_{o}}\left(Q_{11}-Q_{22}-2 Q_{12}-4 Q_{66}\right)\{\sin (4 \phi)-\sin [4(\alpha+\phi)]\} \\
& A_{66}=\frac{1}{4 h_{o}}\left(Q_{11}+Q_{22}-4 Q_{12}\right)\left\{\sin ^{2}(2 \phi)+\cos ^{2}[2(\alpha+\phi)]\right\}+\frac{1}{h_{o}} Q_{66}\left\{\cos ^{2}(2 \phi)+\sin ^{2}[2(\alpha+\phi)]\right\}
\end{aligned}
$$

The longitudinal modulus $E_{x}$ of coupons orientated at an angle $\phi$ about the direction $\mathrm{X}_{1}$ can subsequently be calculated using Eq. (3).

\section{RESULTS AND DISCUSSION}

\subsection{TENSILE PROPERTIES OF CROSS-PLY LAMINATES}

Tensile data for [45/-45] (antisymmetric) T300 stitched mat/urethane 420 IMR laminate coupons are summarized in Table 2, while tensile results for $[45 /-45]_{3 S}$ (symmetric) laminate coupons are presented in Table 3. The tensile strength is defined by the peak load divided by cross-section area, and the strain 
corresponding to the tensile strength is taken as the failure strain. Typical stress-strain curves are shown in Fig. 5 for the $[45 /-45]_{6}$ and in Fig. 6 for the $[45 /-45]_{3 S}$ coupons.

Table 2. Tensile data for $[45 /-45]_{6}$ (antisymmetric) T300 stitched mat/urethane 420 IMR laminate coupons $^{\mathrm{a}}$

\begin{tabular}{ccccc}
\hline $\begin{array}{c}\text { Orientation angle } \\
(\mathrm{deg})\end{array}$ & $\begin{array}{c}\text { Stiffness } \\
(\mathrm{GPa})\end{array}$ & $\begin{array}{c}\text { Tensile strength } \\
(\mathrm{MPa})\end{array}$ & $\begin{array}{c}\text { Failure strain } \\
(\%)\end{array}$ & Poisson's ratio \\
\hline 0 & $45.1 \pm 4.4$ & $513.9 \pm 19.9$ & $1.09 \pm 0.10$ & $0.061 \pm 0.040$ \\
15 & $26.2 \pm 1.8$ & $267.5 \pm 7.8$ & $1.91 \pm 0.30$ & $0.479 \pm 0.109$ \\
30 & $14.0 \pm 1.2$ & $161.9 \pm 4.1$ & $5.97 \pm 0.98$ & $0.700 \pm 0.139$ \\
45 & $11.7 \pm 1.0$ & $140.7 \pm 4.3$ & $5.06 \pm 0.89$ & $0.764 \pm 0.026$ \\
-45 & $10.0 \pm 0.7$ & $131.3 \pm 2.9$ & $4.90 \pm 0.49$ & $0.722 \pm 0.078$ \\
60 & $13.5 \pm 0.9$ & $175.3 \pm 10.0$ & $6.06 \pm 1.48$ & $0.708 \pm 0.043$ \\
70 & $20.1 \pm 2.2$ & $231.3 \pm 16.2$ & $2.96 \pm 0.21$ & $0.574 \pm 0.077$ \\
75 & $26.7 \pm 1.4$ & $260.3 \pm 7.2$ & $1.76 \pm 0.38$ & $0.381 \pm 0.039$ \\
90 & $45.1 \pm 3.8$ & $485.5 \pm 45.2$ & $1.08 \pm 0.09$ & $0.062 \pm 0.020$ \\
\hline
\end{tabular}

${ }^{a}$ Note: The reported data are the average values from at least three specimens with their standard deviations. Results for $15^{\circ}$ and $75^{\circ}$ orientations are new data, and the others have been presented in a previous report. ${ }^{3}$

Table 3. Tensile data for $[45 /-45]_{3 s}$ (symmetric) T300 stitched mat/urethane 420 IMR laminate coupons loaded at various orientations

\begin{tabular}{ccccc}
\hline $\begin{array}{c}\text { Orientation angle } \\
(\mathrm{deg})\end{array}$ & $\begin{array}{c}\text { Stiffness } \\
(\mathrm{GPa})\end{array}$ & $\begin{array}{c}\text { Tensile strength } \\
(\mathrm{MPa})\end{array}$ & $\begin{array}{c}\text { Failure strain } \\
(\%)\end{array}$ & Poisson's ratio \\
\hline 0 & $44.3 \pm 4.5$ & $564.2 \pm 29.5$ & $1.20 \pm 0.08$ & - \\
15 & $29.0 \pm 3.6$ & $251.7 \pm 17.8$ & $1.12 \pm 0.16$ & - \\
30 & $13.2 \pm 1.2$ & $163.6 \pm 7.6$ & $6.04 \pm 0.17$ & - \\
45 & $10.1 \pm 0.9$ & $154.9 \pm 9.2$ & $9.98 \pm 1.39$ & $0.759 \pm 0.061$ \\
60 & $12.2 \pm 0.6$ & $168.6 \pm 0.7$ & $4.64 \pm 1.12$ & $0.553 \pm 0.036$ \\
75 & $24.8 \pm 4.5$ & $229.5 \pm 4.3$ & $1.31 \pm 0.32$ & $0.229 \pm 0.058$ \\
\hline
\end{tabular}

Comparisons of tensile strength, stiffness, and failure strain for the foregoing two types of lay-ups are shown in Figs. 7, 8, and 9, respectively, with bars indicating data scatter.

The above results show that the stress-strain curves, stiffnesses, and strengths are essentially the same for both lay-ups, with tensile properties strongly dependent on loading angles. From Fig. 9, note that the $[45 /-45]_{3 \mathrm{~S}}$ laminate at loading angle $\phi=45^{\circ}$ gives a higher value of failure strain, which may be attributed to its symmetric lay-up configuration.

A comparison of the laminate stiffness obtained from theoretical predictions and the experimental results is shown in Fig. 10. It can be seen that computational results of tensile modulus based on classic laminate theory are in good agreement with the experimental results for both of types of $\left[ \pm 45^{\circ}\right]$ laminates.

\subsection{EFFECT OF SPECIMEN SIZE ON OFF-AXIAL TENSILE PROPERTIES OF CROSS-PLY LAMINATES}

An experimental investigation was conducted to assess the effect of specimen width on the tensile properties of $\left[ \pm 45^{\circ}\right]$ lay-ups. For this purpose, coupons werc cut from the same cross-ply laminate panel 
with widths of $50.8 \mathrm{~mm}(2 \mathrm{in}$.) and $25.4 \mathrm{~mm}(1 \mathrm{in}$.$) , respectively. Results from tensile tests are listed in$ Table 4 . The average tensile strength for the 2 -in.-wide coupons was about $10 \%$ higher than that of their 1-in.-wide counterparts as shown in Fig. 11. The average failure strain for the 2-in.-wide specimens exceeded that of the 1-in.-wide coupons by about $13 \%$. However, the values of tensile modulus and Poisson's ratio were nearly the same for both types of specimens. One plausible explanation for the disparity in the strength between the two sets of coupons can be made using the schematic drawings shown in Fig. 12, which shows that the 1-in.-wide coupon has twice as many unconstrained fibers as the 2-in.wide coupon, when both specimens are of equal length.

Table 4. Comparison of tensile data for $[45 /-45]_{3 \mathrm{~S}}$ (symmetric) T300 stitched mat/urethane $420 \mathrm{IMR}$ laminate coupons with two specimen widths $\left(\phi=45^{\circ}\right)$

\begin{tabular}{ccccc}
\hline $\begin{array}{c}\text { Specimen } \\
\text { Code }\end{array}$ & $\begin{array}{c}\text { Stiffness } \\
\text { (GPa) }\end{array}$ & $\begin{array}{c}\text { Tensile strength } \\
\text { (MPa) }\end{array}$ & $\begin{array}{c}\text { Failure strain } \\
(\%)\end{array}$ & Poisson's ratio \\
\hline & \multicolumn{4}{c}{ 2-in.-wide coupons } \\
C54-2in45-1 & 10.3 & 173.8 & 11.03 & 0.797 \\
C54-2in45-2 & 10.4 & 168.2 & 9.73 & 0.763 \\
C54-2in45-3 & 10.0 & 164.6 & 10.58 & 0.715 \\
C54-2in45-4 & 11.0 & 160.7 & 10.17 & 0.769 \\
C54-2in45-5 & 9.6 & 177.5 & 11.22 & 0.797 \\
C54-2in45-6 & 9.2 & 175.7 & 16.30 & 0.882 \\
Average & $10.1 \pm 0.7$ & $170.1 \pm 6.7$ & $11.51 \pm 2.41$ & $0.787 \pm 0.055$ \\
& & $1-$ in.-wide coupons & & \\
C54-1in45-1 & 11.3 & 169.5 & 11.08 & 0.799 \\
C54-1in45-2 & 9.8 & 148.7 & 10.43 & 0.742 \\
C54-1in45-3 & 9.4 & 149.6 & 10.65 & 0.761 \\
C54-1in45-4 & 10.1 & 144.6 & 7.23 & 0.704 \\
C54-1in45-5 & 10.8 & 160.5 & 10.00 & 0.692 \\
C54-1in45-6 & 9.0 & 156.3 & 10.49 & 0.855 \\
Average & $10.1 \pm 0.9$ & $154.9 \pm 9.2$ & $9.98 \pm 1.39$ & $0.759 \pm 0.061$ \\
\hline
\end{tabular}

It may be recalled that under monotonically increasing tensile loading of coupons oriented obliquely to the load direction, the stress-strain relationship changes gradually from linearity to nonlinearity, as shown in Figs. 5 and 6. Within the linear elastic range, which occurs at the early stage of loading, the deformation is not effected by constraint conditions. However, when the applied stress exceeds the elastic limit of the matrix and/or the shear strength of fiber-matrix interface, inelastic deformation occurs, and the unconstrained fibers within the specimen will either slip or rotate by means of a "scissoring action" until the attainment of shear failure. Weak locations are likely to develop within the unconstrained region, where tensile failure does occur. Consequently, the presence of a larger number of unconstrained fibers in the 1-in.-wide specimens would result in the lowering of both strength and failure strain, when compared to the instance of 2-in.-wide specimens. Conversely, note that the recorded increase in the strength of wider $\left[ \pm 45^{\circ}\right]$ graphite/epoxy coupons has been attributed by others to gripping effects. ${ }^{4}$ Because both tensile modulus and Poisson's ratio were determined within the linear range of stress-strain curves, little or no difference in these values is expected for both types of specimens. 


\subsection{TENSILE PROPERTIES OF [0/90/45/-45]s (QUASI-ISOTROPIC) LAMINATES}

Tensile data for the nominally [0/90/45/-45] $]_{S}$ (quasi-isotropic) laminate are shown in Table 5 . Typical stress-strain curves for the test coupons at different loading angles are shown in Fig. 13. The tensilc moduli that correspond to the experimental data are shown in Fig.14, together with data scatter bands, where they are compared against the value of the ideal quasi-isotropic laminate.

According to laminate theory, tensile properties of quasi-isotropic laminates should not depend on load direction. However, some differences in tensile properties and deviations from the predicted values have been found for various loading angles. The plausible explanation is that these differences were induced by small misalignment of plies in the laminates, due to misalignments in the original stitch-bonded mats. As shown in Fig. 4, assuming a misalignment angle $\alpha$, the tensile moduli at different loading angles can be calculated by Eqs. (5) and (3). Figure 15 exhibits calculated values of laminate stiffnesses at different loading orientations, with $\alpha$ varying from $0^{\circ}$ up to $20^{\circ}$. It is evident that, with increasing the lay-up misalignment angle $\alpha$, the tensile moduli depart more significantly from the ideal value of $\alpha=0^{\circ}$. Accordingly, lay-up misalignment has a significant effect on the mechanical response of laminates, and the accuracy in lamina alignment during the lay-up process is of key importance for attaining the desired properties of laminates.

Table 5. Tensile data for $[0 / 90 / 45 /-45]_{\mathrm{S}}$ (quasi-isotropic) T300 stitched mat/urethane $420 \mathrm{IMR}$ laminate coupons loaded at various orientations

\begin{tabular}{cccc}
\hline $\begin{array}{c}\text { Orientation angle } \\
\text { (Degree) }\end{array}$ & $\begin{array}{c}\text { Stiffness } \\
\text { (GPa) }\end{array}$ & $\begin{array}{c}\text { Tensile strength } \\
\text { (MPa) }\end{array}$ & $\begin{array}{c}\text { Failure strain } \\
(\%)\end{array}$ \\
\hline 0 & $34.4 \pm 1.6$ & $335.7 \pm 5.2$ & $0.96 \pm 0.05$ \\
15 & $30.4 \pm 0.9$ & $252.0 \pm 32.0$ & $0.86 \pm 0.11$ \\
30 & $26.9 \pm 0.8$ & $277.7 \pm 5.0$ & $1.09 \pm 0.03$ \\
45 & $33.7 \pm 0.9$ & $308.6 \pm 15.8$ & $0.92 \pm 0.04$ \\
90 & $31.5 \pm 1.0$ & $307.0 \pm 7.8$ & $0.96 \pm 0.03$ \\
\hline
\end{tabular}

Note, however, that the results shown in Fig. 15 correspond to the assumed misaligned configuration depicted in Fig. 4. This configuration may or may not correspond to the actual misalignments that occur during the lay-up process. Due to practical limitations, it is only possible to measure the angular misalignment between the exposed outer layers of the laminate. Nevertheless, an analysis of the "idealized" misaligned lay-up shown in Fig. 4 can provide a reasonable correlation with the magnitude of misalignment angles that occurred during actual lay-up processes*.

It can be seen that the ratio between the maximum and minimum stiffness values in Fig. 14 is about 0.78 ; according to Fig. 15 , this ratio is 0.79 when the misalignment angle is $\alpha=10^{\circ}$. This implies that there may have been $a \sim 10^{\circ}$ departure from ideal quasi-isotropic lay-up within the laminate panel that was tested in this study. Such angular deviations were indeed observed between the directions of fibers in the outer plies of the laminate.

\footnotetext{
*Although a wide scope of probabilities exists for the locations of the misaligned plies, the in-plane stiffnesses of the laminate are highly insensitive to any particular ordering of those locations within the laminate.
} 


\subsection{COMPARISON OF TENSILE PROPERTIES OF THREE LAMINATES WITH DIFFERENT LAY-UPS}

Tensile strength, failure strain, and stiffness of the three laminates with different lay-ups were replotted together and are shown in Figs. 16, 17, and 18. As noted earlier, all the tensile properties for $\left[ \pm 45^{\circ}\right]$ laminates vary greatly with respect to loading angles, but this angular dependence is less pronounced for the quasi-isotropic lay-ups. The angular dependence, which is nevertheless observed in the response of the latter circumstance, is attributed to misalignments in laminate lay-ups, as discussed above. Tensile coupons with a quasi-isotropic lay-up also show lower values of failure strain, when compared to the other two types of laminates. This disparity in failure strains is consistent with the failure behavior of the three laminates. From the tensile stress-strain curves shown in Figs. 5, 6, and 13, sudden failures occurred in tension of $[45 /-45]_{6}$ and $[45 /-45]_{3 S}$ laminates at $\phi=0^{\circ}$ and $90^{\circ}$, as was the case for the $[0 / 90 / 45 /-45]_{\mathrm{s}}$ laminate under all loading angles. Conversely, the delayed failures observed for $[45 /-45]_{6}$ and $[45 /-45]_{3 \mathrm{~s}}$ laminates at loading angles $\phi$, other than $0^{\circ}$ and $90^{\circ}$, resulted in higher values of failure strains.

\subsection{INTERNAL DAMAGE DEVELOPMENT UNDER EXTERNAL LOADING}

To identify the influence of stress levels on internal damage of laminate coupons, test coupons were subjected to progressively stepped-up load levels [in percentage of ultimate tensile strength, (\%UTS)]. Upon reaching the desired stress level, the load was maintained for 4 min, when penetrating liquid was applied on surfaces of the coupon, especially on edges. As noted earlier, the load was subsequently removed, and the coupon was immersed in the penetrant liquid for several hours. The $\mathrm{x}$-ray photographs were then taken, and the specimen was reloaded to the next stress level.

For the tensile coupons with large loading angles such as $\phi=45^{\circ}\left(-45^{\circ}\right)$ or $30^{\circ}\left(60^{\circ}\right)$, extensive internal damage was accumulated prior to final failure. The stress-strain curves of two specimens with loading angle $\phi=45^{\circ}$ are shown in Fig. 19, and their corresponding X-ray images are presented in Figs. 20(a) and (b). Stress-strain curves for both specimens show gradual flattening with increasing stress levels, indicating degradation of the materials due to prior loading history. The x-ray images also clearly show flaws developing in the two test coupons at stress levels above 40\%UTS.

Loading-unloading cycling with successively increasing stress levels was also carried out on several specimens to investigate the process of internal damage growth. Typical loading-unloading stress-strain curves for a $[45 /-45]_{3 S}$ laminate coupon, with loading oriented at $\phi=45^{\circ}$, are shown in Fig. 21 . With increasing load levels, both the areas enclosed within the stress-strain curves ("hysteresis loops") and the residual strains increase as well, attesting to growth in irreversible internal damage mechanisms. Prior loading histories also reduce the stiffness of tensile coupons. This is shown in Fig. 22, where stiffness reduction of thrce test coupons is plotted vs the highest level of prior tensile stress applied to the specimen. These coupons are the same specimens shown in Figs. 19 and 21.

For tensile coupons tested at smaller loading angles, such as $\phi=0^{\circ}\left(90^{\circ}\right)$ or $15^{\circ}\left(75^{\circ}\right)$, the stress-strain relationship is nearly linear up to final failure, as exhibited by the corresponding curves in Figs. 5 and 6 . In such cases, no extensive internal damages were recorded in X-ray photographs. Typical X-ray images are shown in Fig. 23 for a cross-ply specimen at a loading angle $\phi=15^{\circ}$. No perceptible damage was detected even at a stress level as high as $60 \%$ UTS.

For the tensile coupons with quasi-isotropic lay-ups, the stress-strain curves at all loading angles are nearly linear until failure, as shown in Fig. 13. Loading-unloading curves of a typical quasi-isotropic coupon are shown in Fig. 24, and the corresponding X-ray photographs are illustrated in Fig. 25. The 
coupon shows insignificant residual strains upon unloading and little or no hysteresis loops due to load cycling. These observations imply that the deformation of the specimen under tensile load is mainly elastic and that final failure is likely triggered by the sudden failure of the fibers. The above suppositions are supported by the X-ray photographs shown in Fig. 25, which exhibit no noticeable damage cven when the loading stress is as high as $90 \%$ UTS.

The failure behavior of cross-ply tensile coupons with large loading angles, namely $|\phi| \geq 30^{\circ}$, where the fibers are oriented obliquely to the load directions, appears to be dominated by failure processes within the matrix resin, as well as by the bonding strength of fiber-matrix interface. Consequently, the mechanical response of the above specimens is time-dependent, as is commonly the case for polymer materials. However, for the tensile coupons with small loading angles, as well as for quasi-isotropic coupons at all angular orientations, failure is dominated by the fibers, which are linearly elastic in nature. Therefore, the stress-strain curves for these kinds of specimens are nearly linear up to failure.

\subsection{CREEP AND RECOVERY BEHAVIOR OF CROSS-PLY LAMINATE COUPONS}

\subsubsection{Influence of Creep Stress Levels}

The creep and recovery behavior of cross-ply laminate coupons was found to be highly influenced by the level of applied creep stress. Typical creep and recovery curves of [45/-45 $]_{3 \mathrm{~S}}$ laminate coupons under various creep stresses at a loading angle $\phi=45^{\circ}$ are shown in Fig. 26. Generally, both creep rates and amplitudes of residual (permanent) strains increase with the magnitude of applied stress. High creep stresses also cause extensive internal damage within the coupons as shown by the X-ray images in Fig. 27. This figure exhibits the growing defects induced by increase in creep loads.

\subsubsection{Influence of Loading Angles}

Creep and recovery responses under increasing loading angles for the $\left[ \pm 45^{\circ}\right]$ coupons resemble the behavior observed under increasing tensile stresses. Creep and recovery curves for four laminate coupons subjected to stresses of $60 \%$ UTS with different loading angles are presented in Fig. 28. Creep rates and residual permanent strains were found to increase with loading angles. Coupons with small loading angles, such as $|\phi| \geq 15^{\circ}$, give a more rapid recovery of creep strains.

\section{CONCLUDING REMARKS}

A systematic experimental and analytical investigation of the mechanical response of stitched T300 mat/urethane 420 IMR composite laminates revealed the following:

1. Tensile properties of $[45 /-45]_{6}$ (antisymmetric) and $[45 /-45]_{35}$ (symmetric) laminates are strongly dependent on loading directions, but this dependence is much weaker for the nominally $[0 / 90 / 45 /-45]_{S}$ (quasi-isotropic) laminates.

2. Lay-up sequences of cross-ply laminates do not seem to influence their tensile properties.

3. Misalignment of plies, occurring during the fabrication of quasi-isotropic laminates, reduces their tensile properties and induces angular dependence in stiffness values, which may deviate from intended properties of ideal quasi-isotropic laminates.

4. Classical laminate theory is capable of predicting the tensile properties of stitched laminates within linear range. 
5. Internal damage of laminated coupons depends on loading history, applied stress, and loading angle.

6. The creep and recovery response of laminate coupons is dependent on both applied load level and loading angle.

\section{REFERENCES}

1. J. M. Corum et al., Basic Properties of Reference Crossply Carbon-Fiber Composite, Lockheed Martin Energy Research, Oak Ridge National Laboratory, Report ORNL-TM-2000/29, February 2000.

2. I. M. Daniel and O. Ishai, Engineering Mechanics of Composite Materials, Oxford University Press, 1994.

3. J. Gao and Y. J. Weitsman, The Tensile Mechanical Properties and Failure Behavior of Stitched T300 Mat/Urethane 420 IMR Composite, Contract Technical Report, MAES98-2.0-CM, The University of Tennessee, July 1998.

4. S. Kellas et al., "Damage and Failure Mechanisms in Scaled Angle-Ply Laminates," pp. 257-280, in Composite Materials Fatigue and Fracture, (W. Stinchcomb and N. E. Eshbaugh, editors), ASTM STP 1156, ASTM, 1993. 


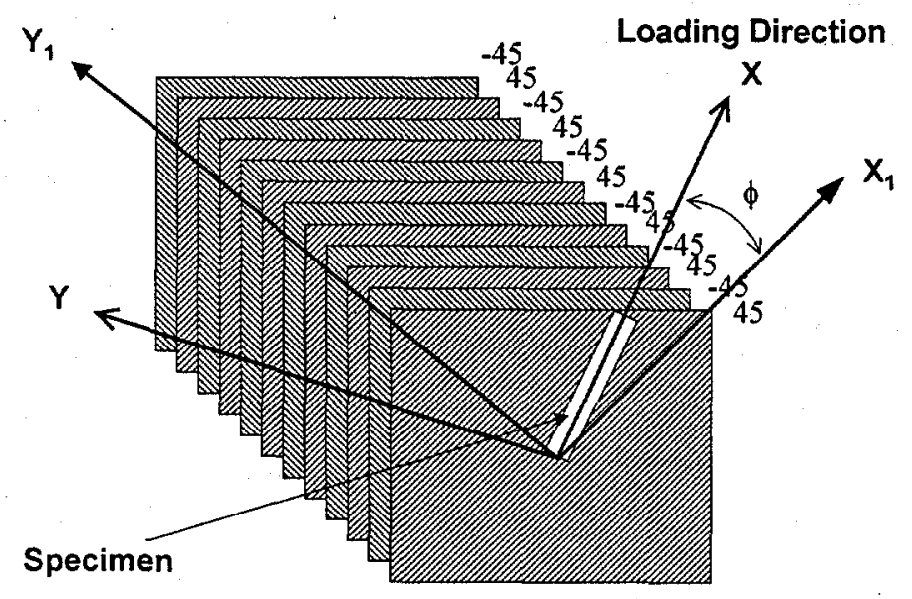

(a) $[45 /-45]_{6}$ (Antisymmetric)

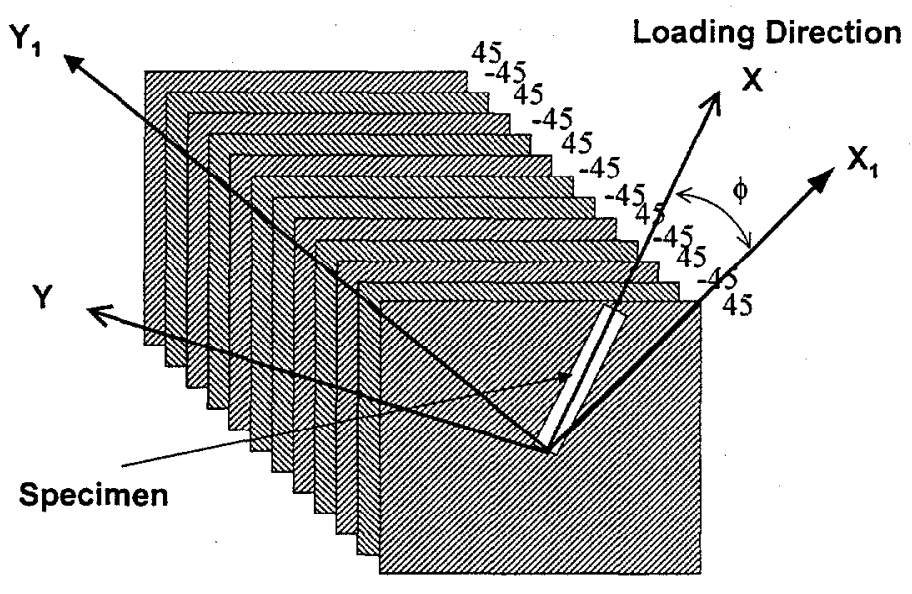

(b) $[45 /-45]_{3 s}$ (Symmetric)

Fig. 1. Schematic drawings of cross-ply stitched T300 mat/urethane 420 IMR laminates with two lay-up sequences.

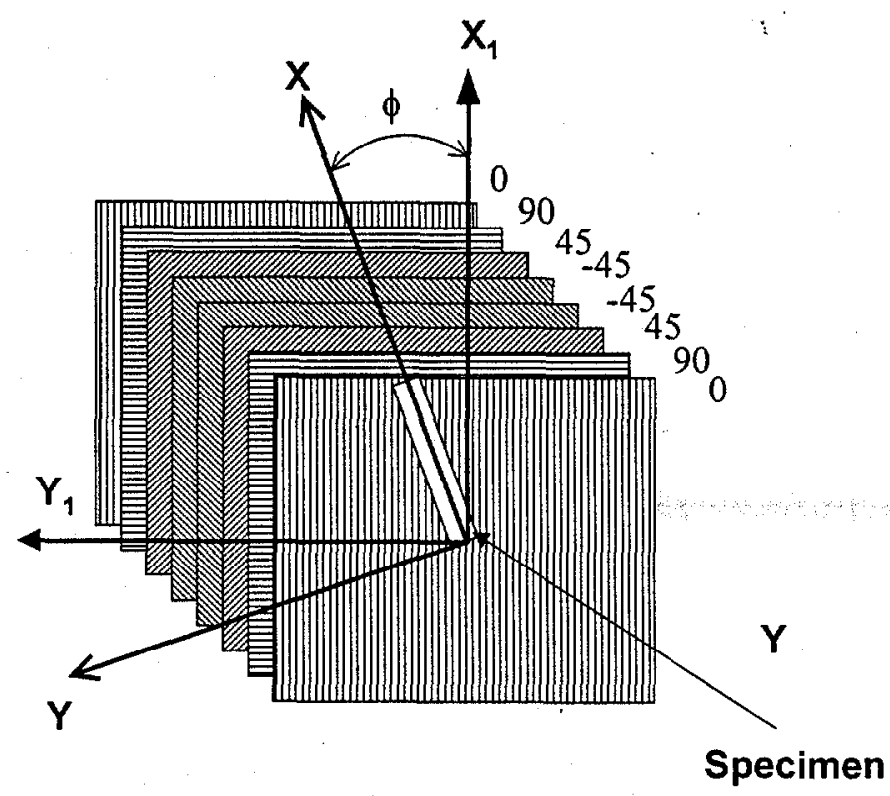

Fig. 2. Schematic drawing of [0/90/45/-45 $]_{3 S}$ quasi-isotropic T300 stitched mat/urethane 420 IMR laminate. 


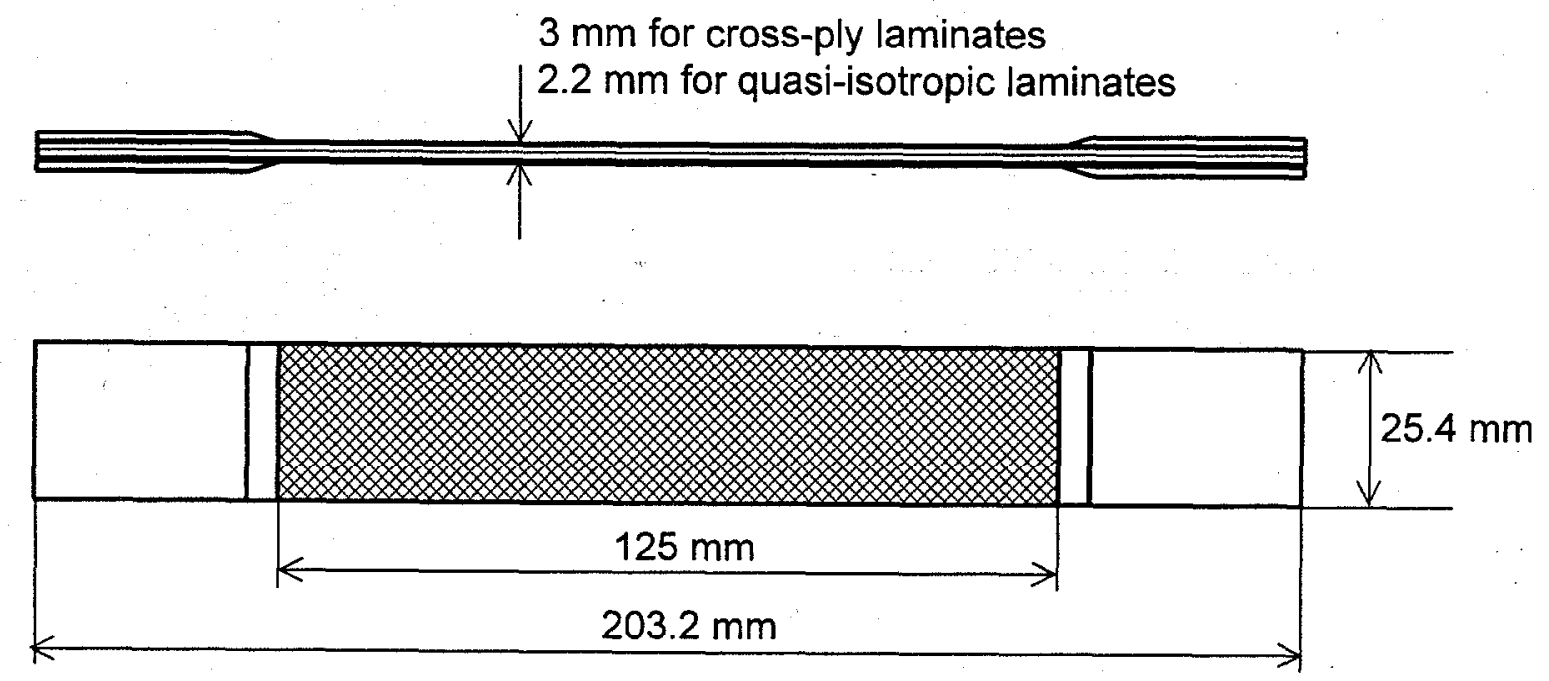

Fig. 3. Illustration of a test coupon for tensile and creep and recovery tests. 


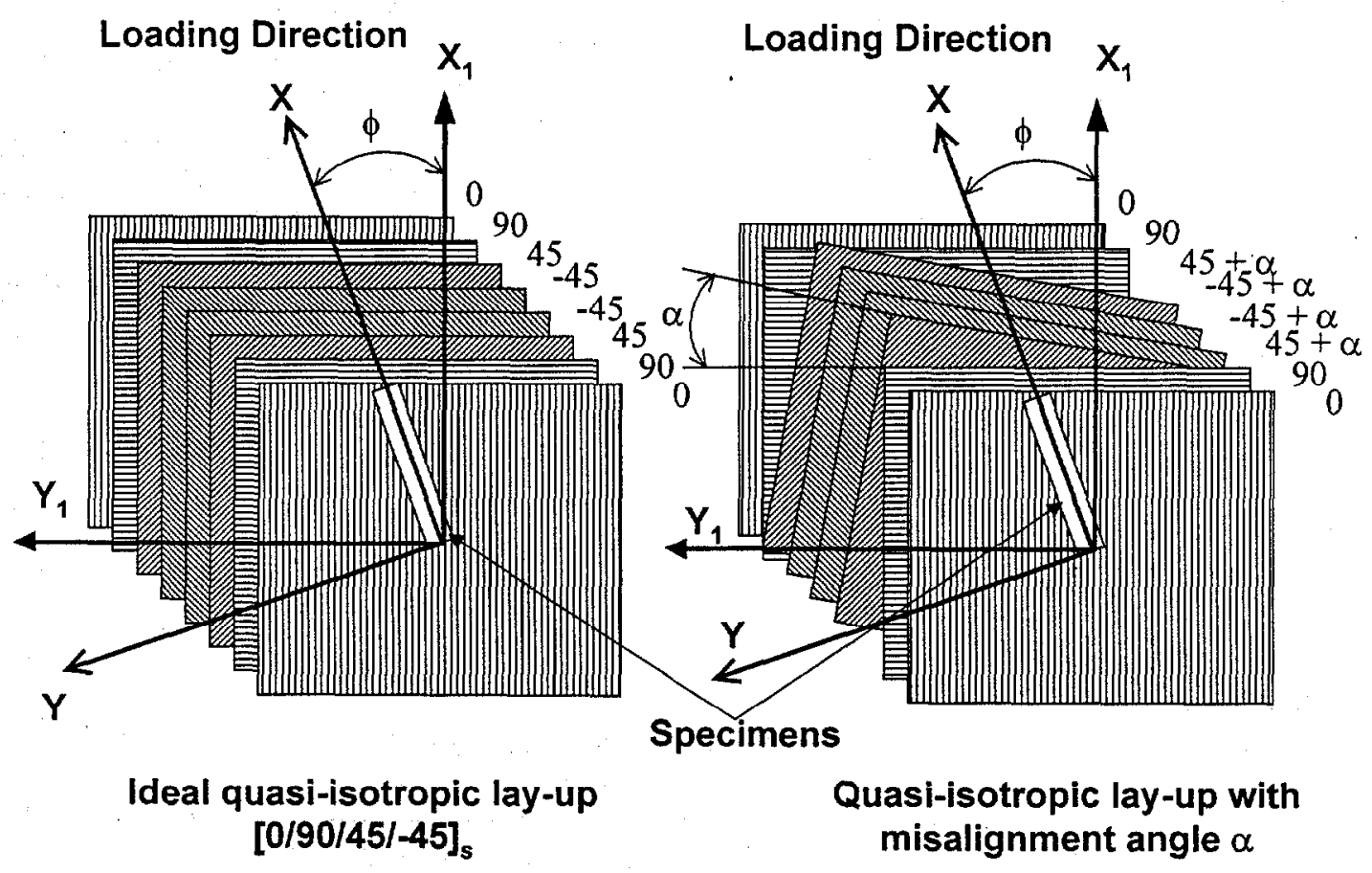

Fig. 4. Illustration of quasi-isotropic laminate with lay-up misalignment. 


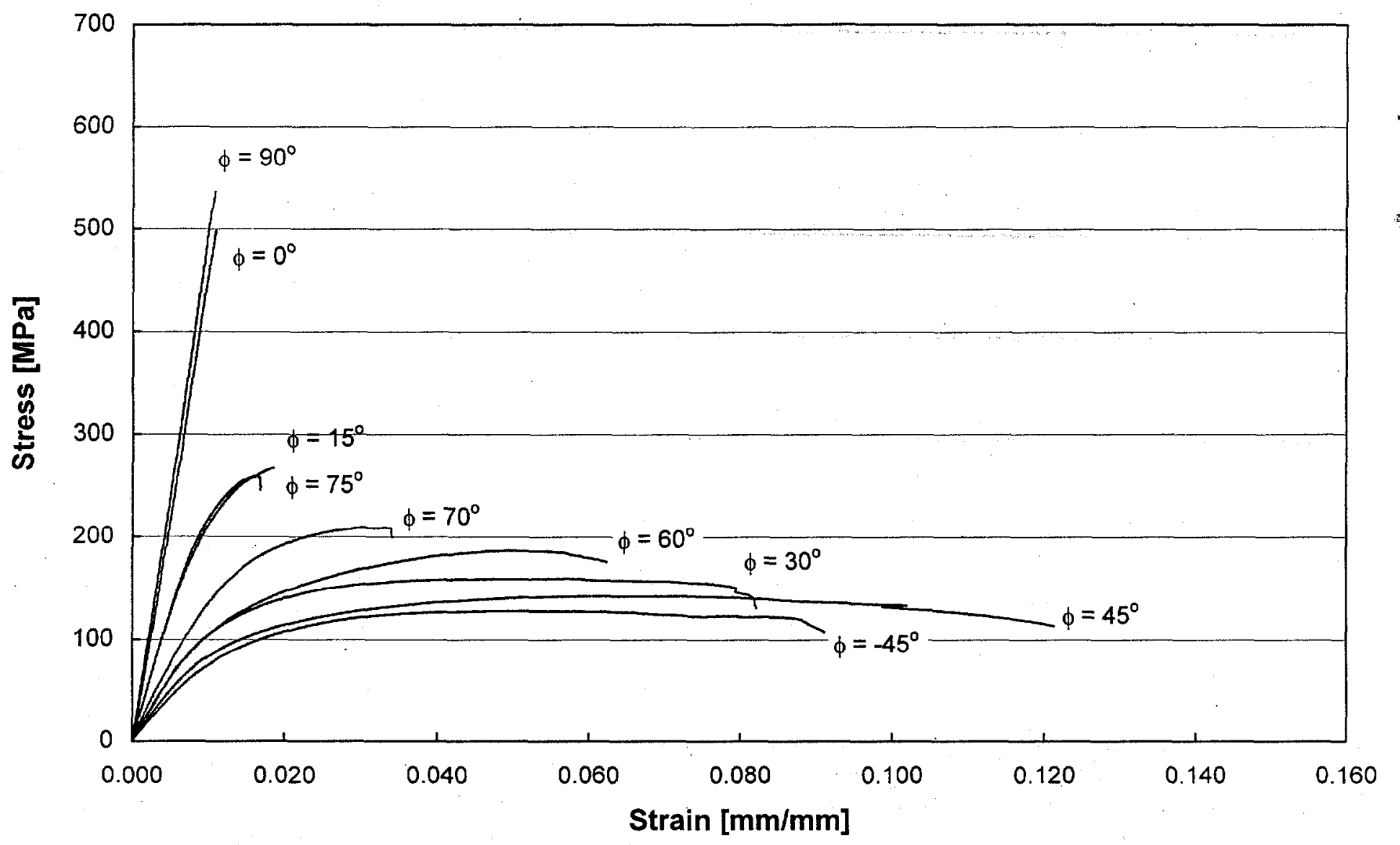

Fig. 5. Typical stress-strain curves of [45/-45] 6 stitched T300 mat/urethane 420 IMR composites. 


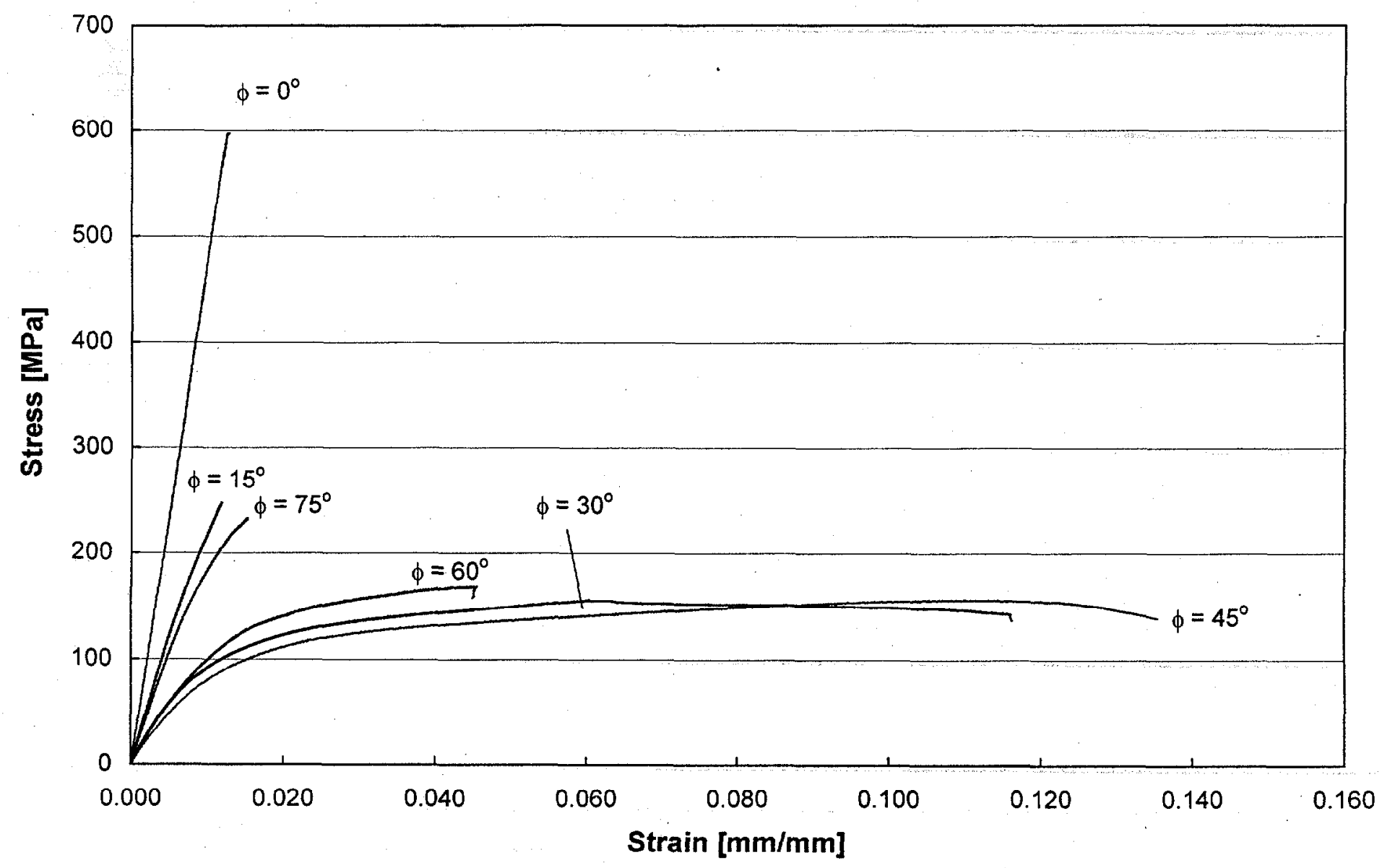

Fig. 6. Typical stress-strain curves of $[45 /-45]_{3 S}$ stitched T300 mat/urethane 420 IMR composites. 


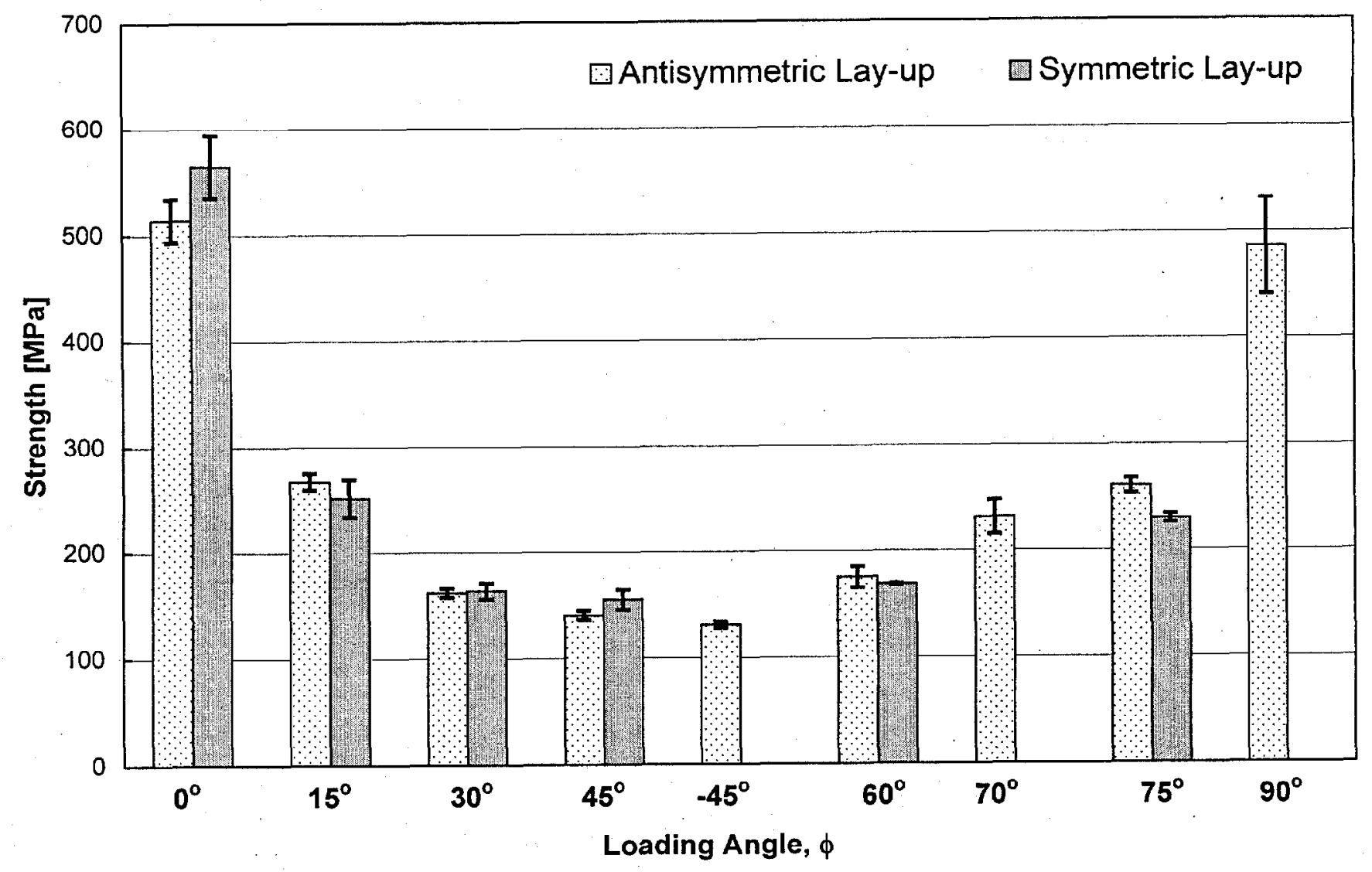

Fig. 7. Strength vs loading angle of $[45 /-45]_{6}$ and $[45 /-45]_{3 \mathrm{~S}}$ stitched T300 mat/urethane $420 \mathrm{IMR}$ composites. 


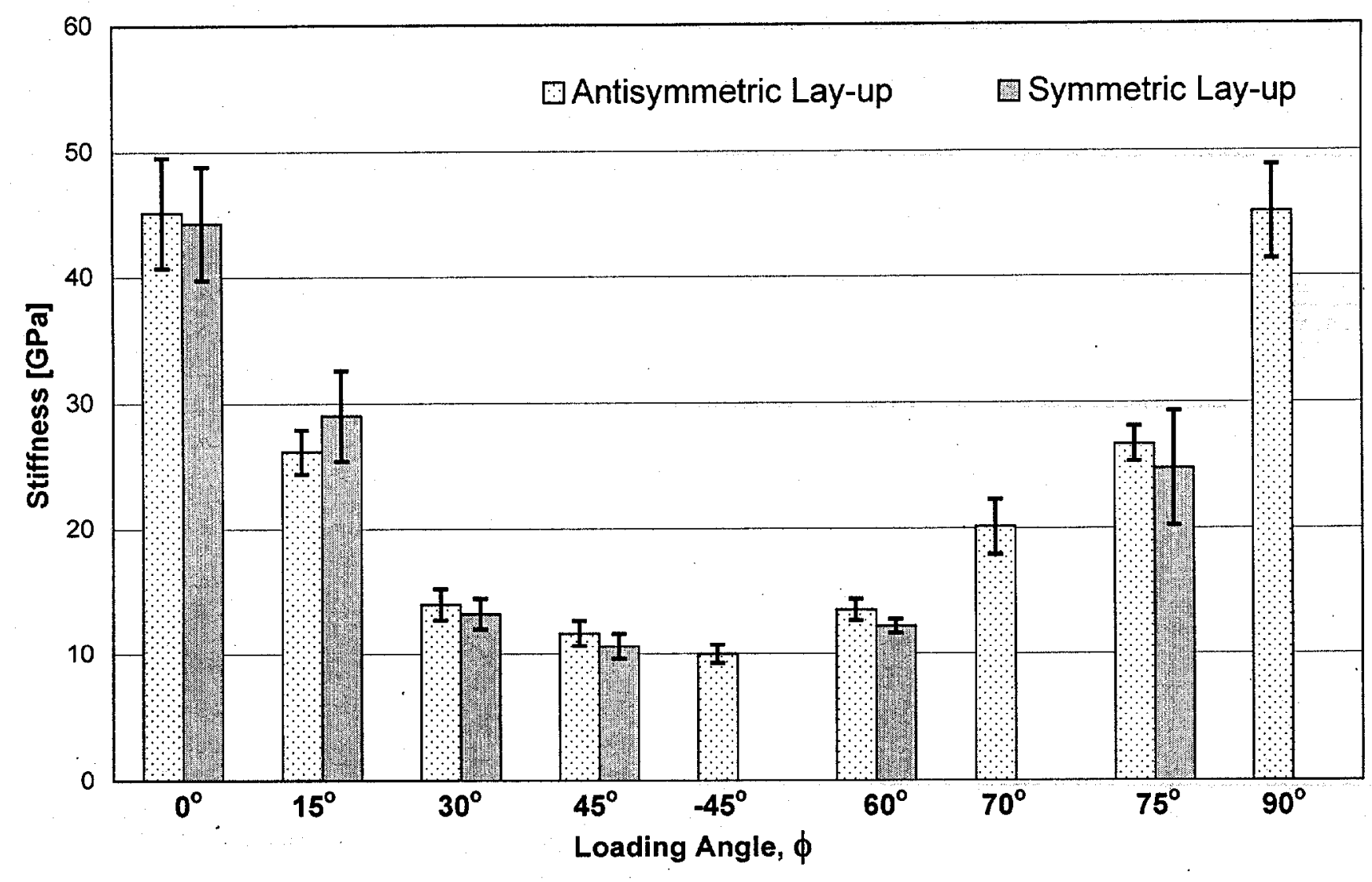

Fig. 8. Stiffness vs loading angle of $[45 /-45]_{6}$ and $[45 /-45]_{3 s}$ stitched T300 mat/urethane 420 IMR composites. 


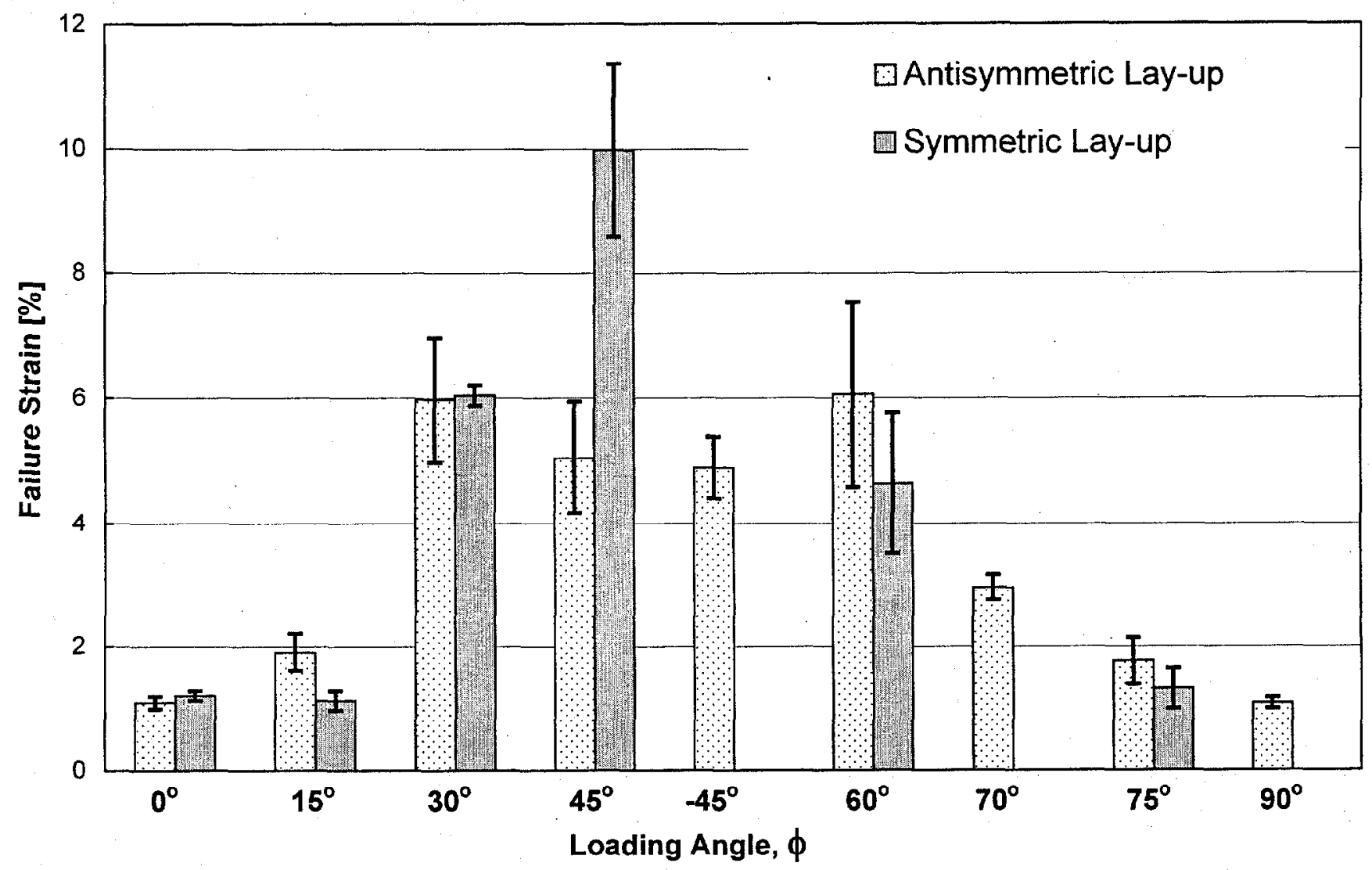

Fig. 9. Failure strain vs loading angle of $[45 /-45]_{6}$ and $[45 /-45]_{3 s}$ stitched T300 mat/urethane 420 IMR composites. 


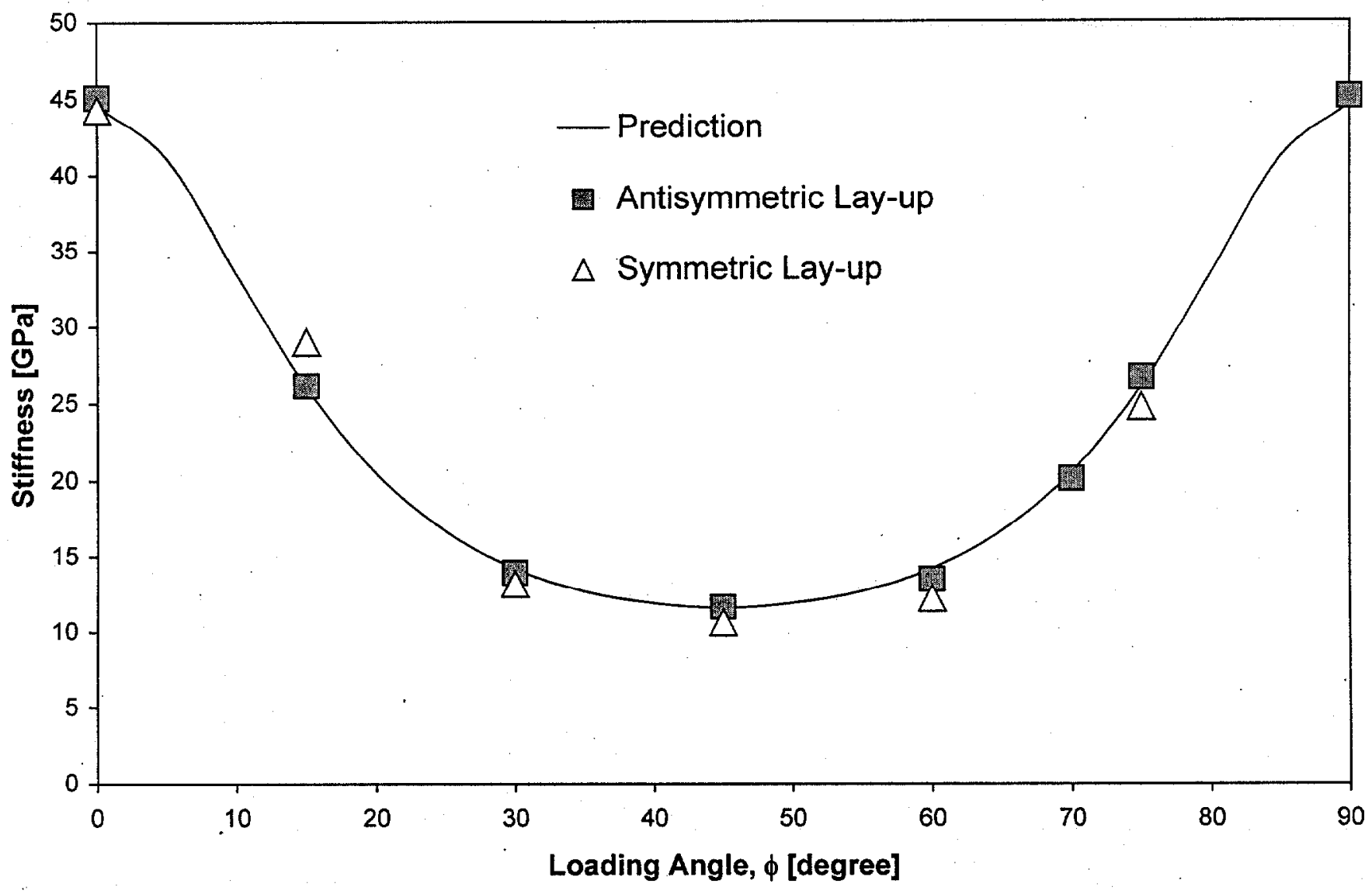

Fig. 10. Variations in tensile stiffness vs loading orientation for $[45 /-45]_{6}$ and $[45 /-45]_{3 S}$ composite laminates and comparison with predictions of classical laminate theory. 


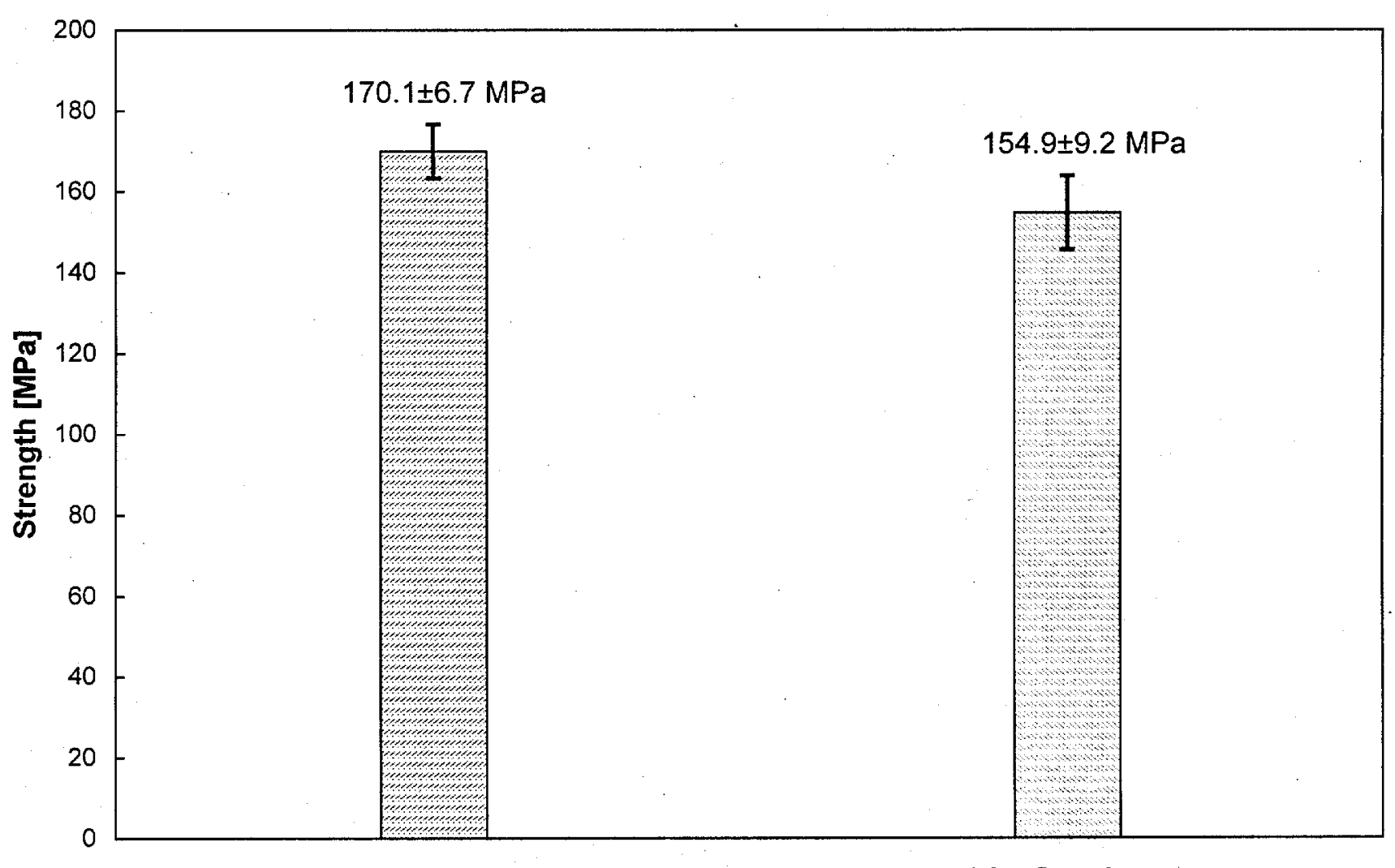

2-in. Specimen

1-in. Specimen

Fig. 11. Tensile results of test coupons with two different widths, showing the influence of specimen size on the strength of $\left[ \pm 45^{\circ}\right]_{3 s}$ laminates. 
Fibers are constrained at one end

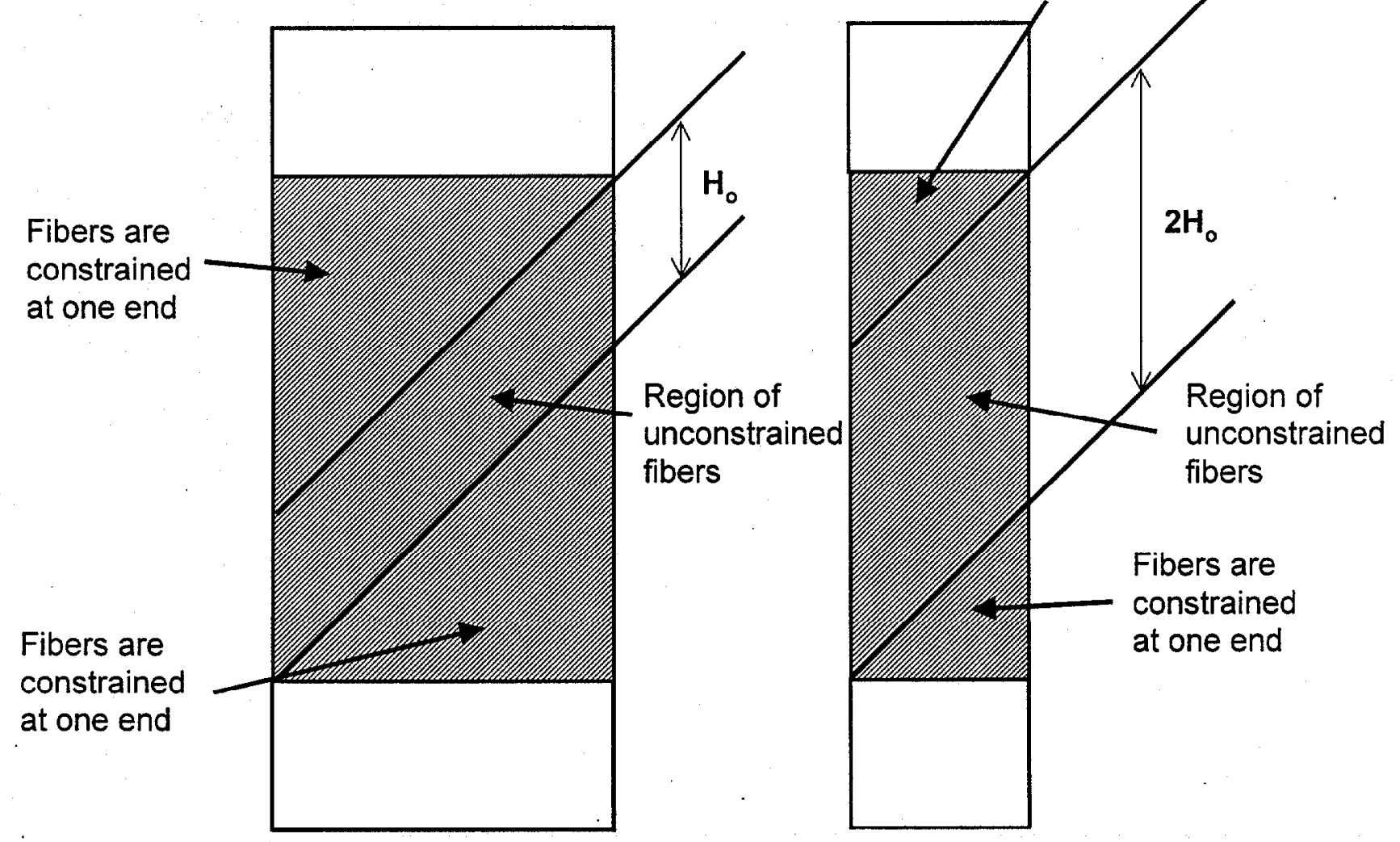

Fig. 12. Schematic drawings of test coupons with two different widths, showing larger proportion of unconstrained fibers in the narrower specimen. 


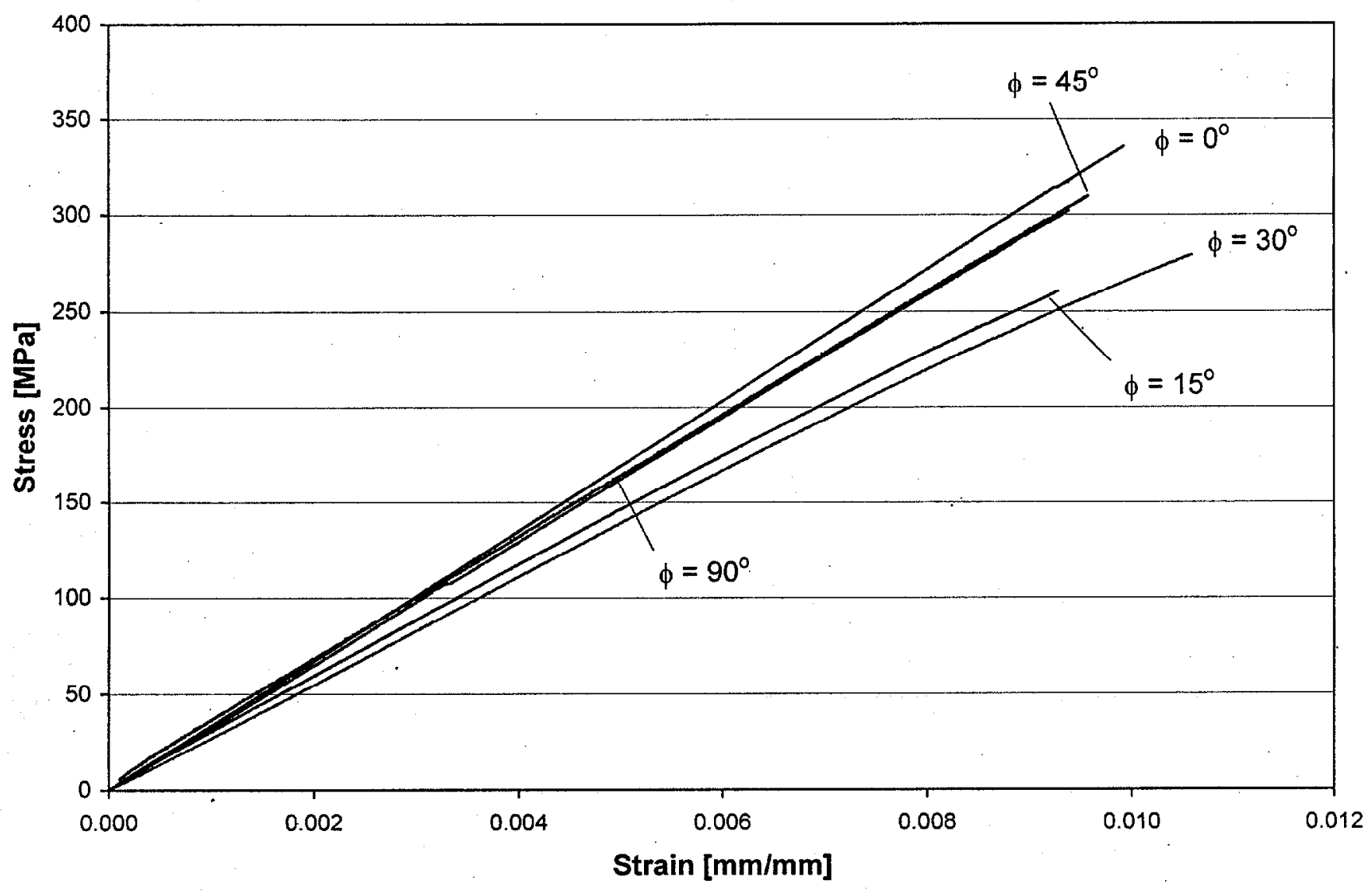

Fig. 13. Typical stress-strain curves of $[0 / 90 / 45 /-45]_{\text {s }}$ quasi-isotropic stitched T300 mat/urethane 420 IMR composites at various orientations. 


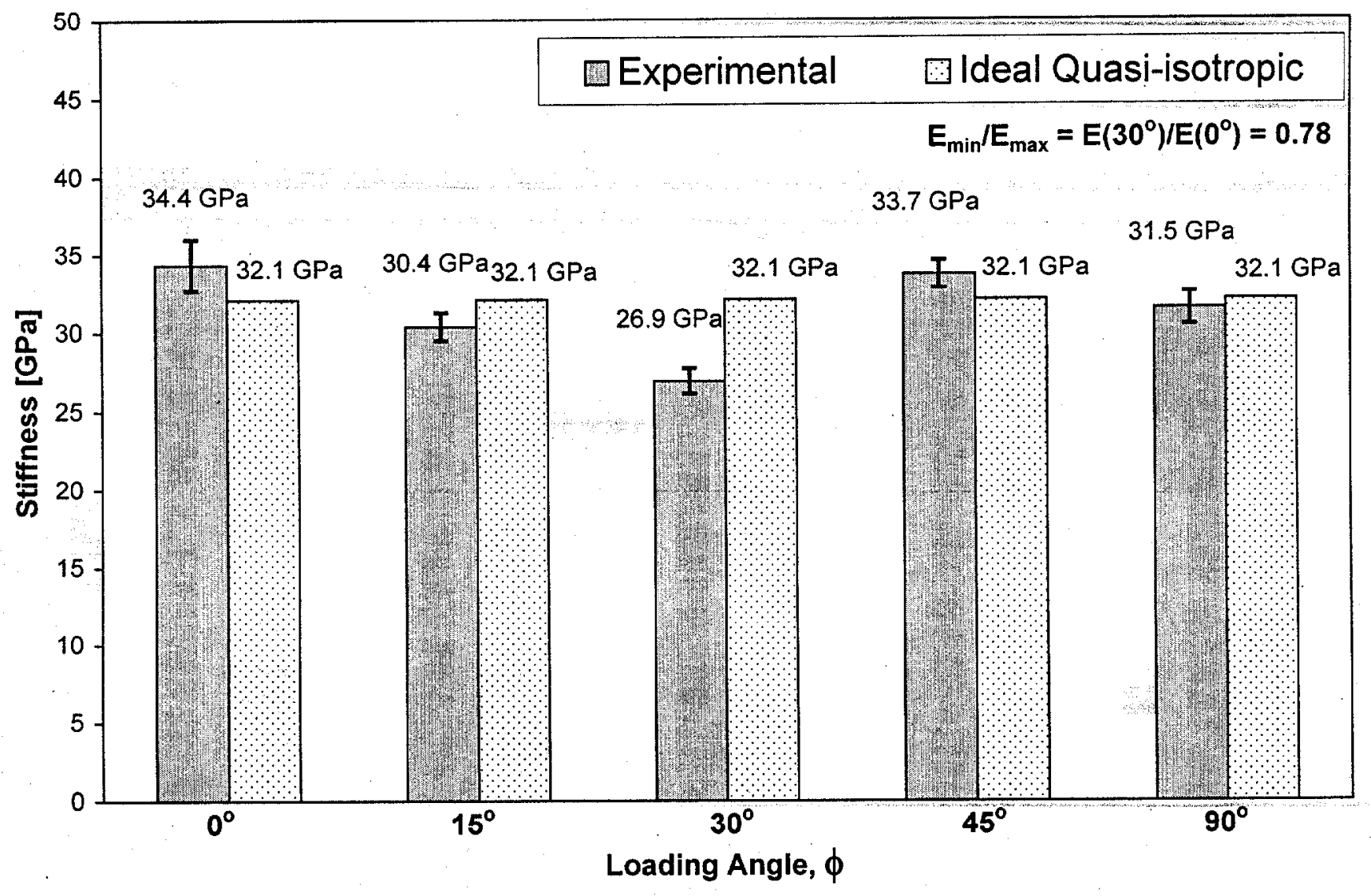

Fig. 14. Stiffness vs orientation angle of [0/90/45/-45]s quasi-isotropic stitched T300 mat/urethane 420 IMR composites. (The values for ideal quasi-isotropic laminates are calculated using laminate theory.) 


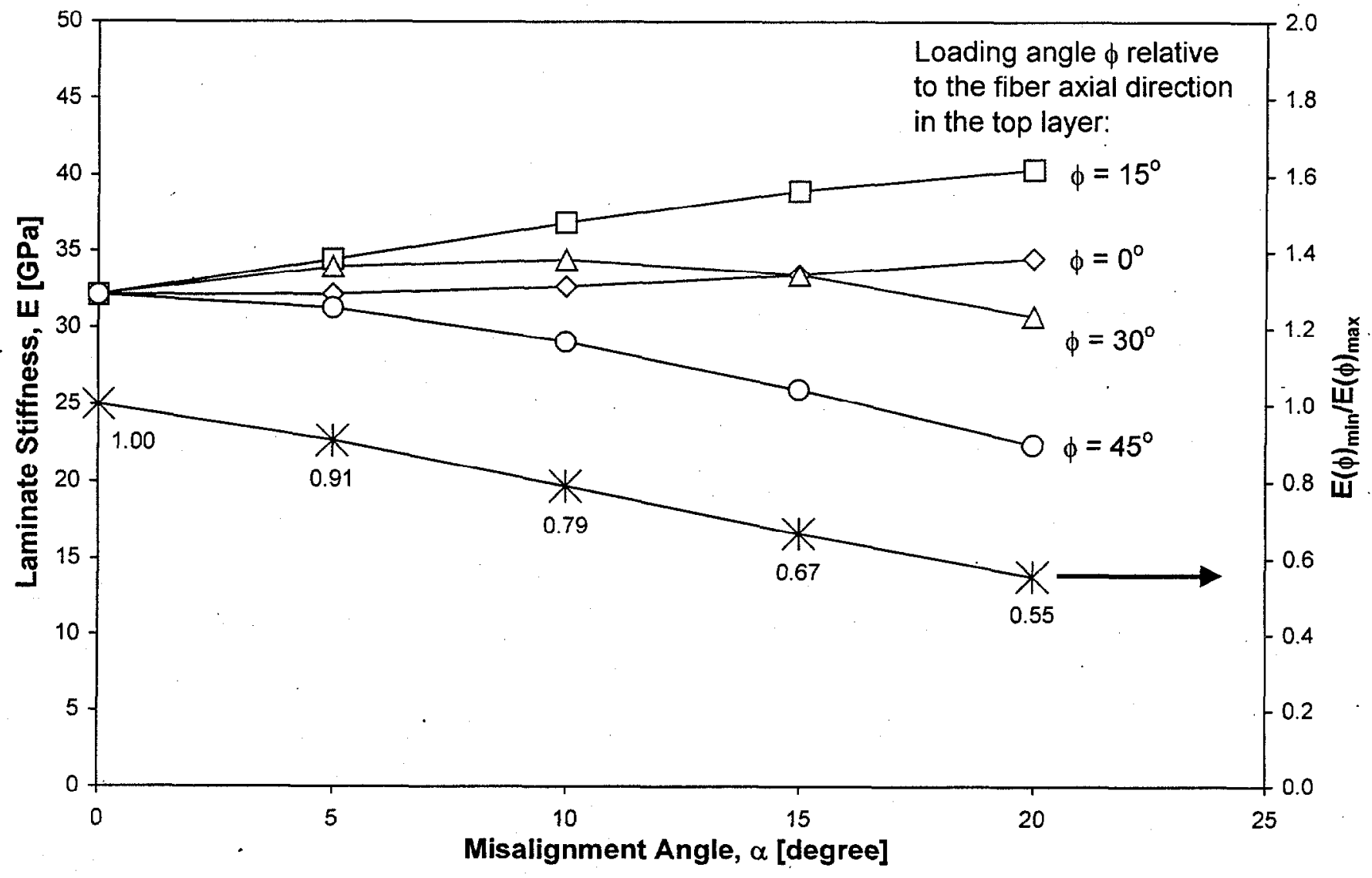

Fig. 15. Influence of laminate lay-up misalignment on the stiffness of [0/90/45/-45 $]_{\mathrm{s}}$ quasi-isotropic stitched T300 mat/urethane 420 IMR composites. 


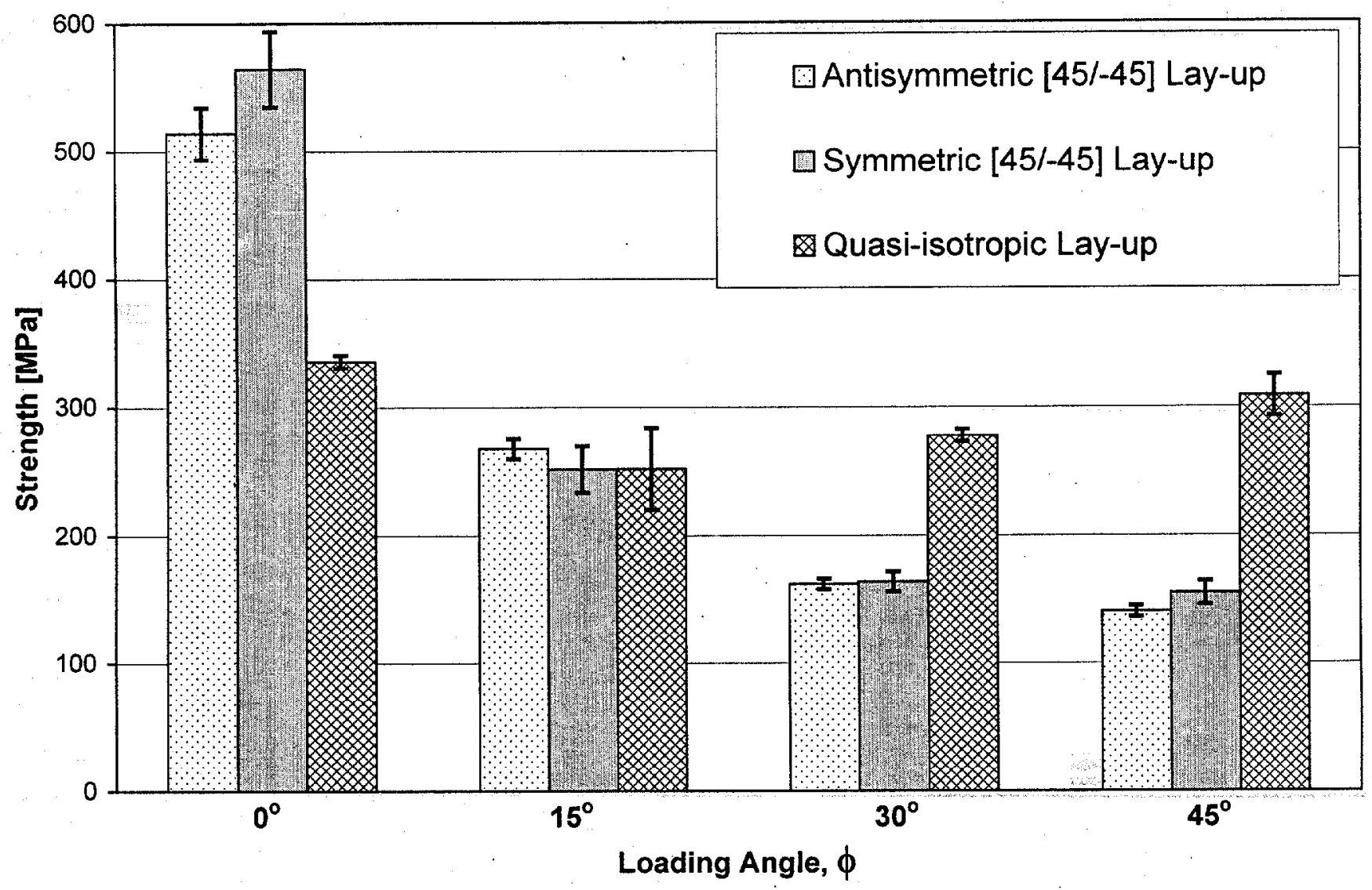

Fig. 16. Comparison of tensile strengths of stitched T300 mat/urethane 420 IMR composites with different laminate lay-ups. 


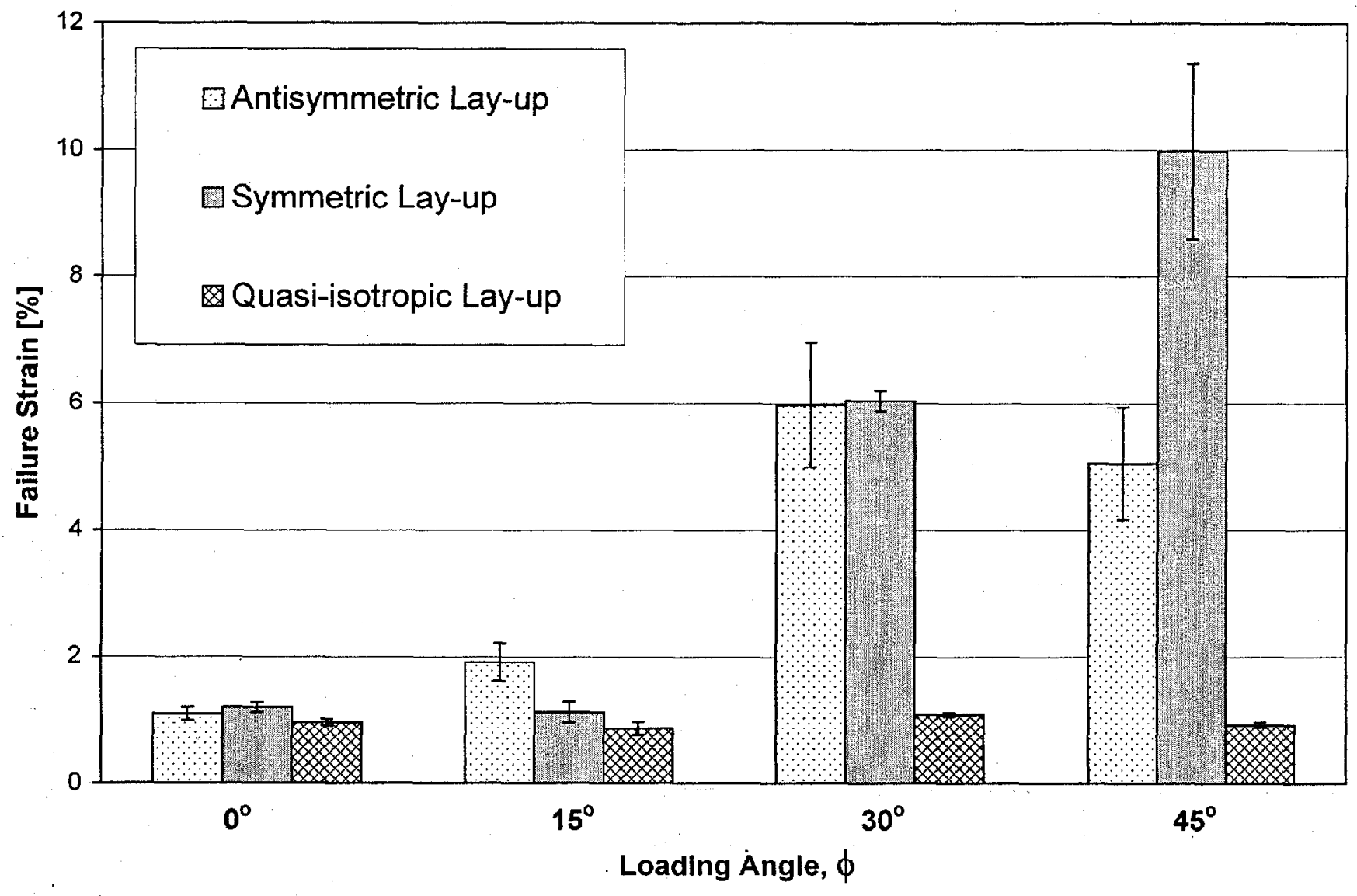

Fig. 17. Comparison of failure strains of stitched T300 mat/urethane 420 IMR composites with different laminate lay-ups. 


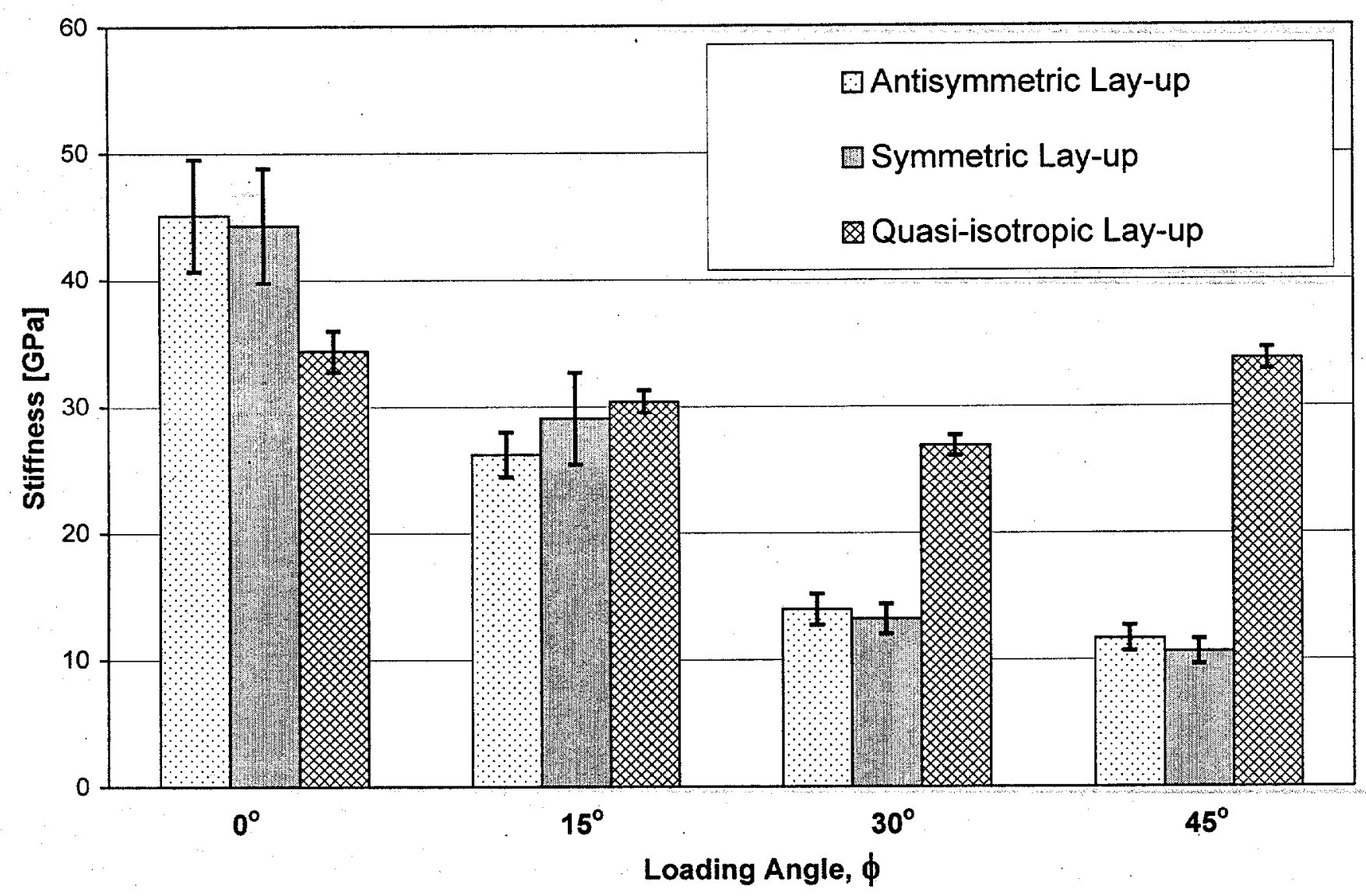

Fig. 18. Comparison of linear-elastic tensile moduli of stitched T300 mat/urethane 420 IMR composites with different laminate lay-ups. 

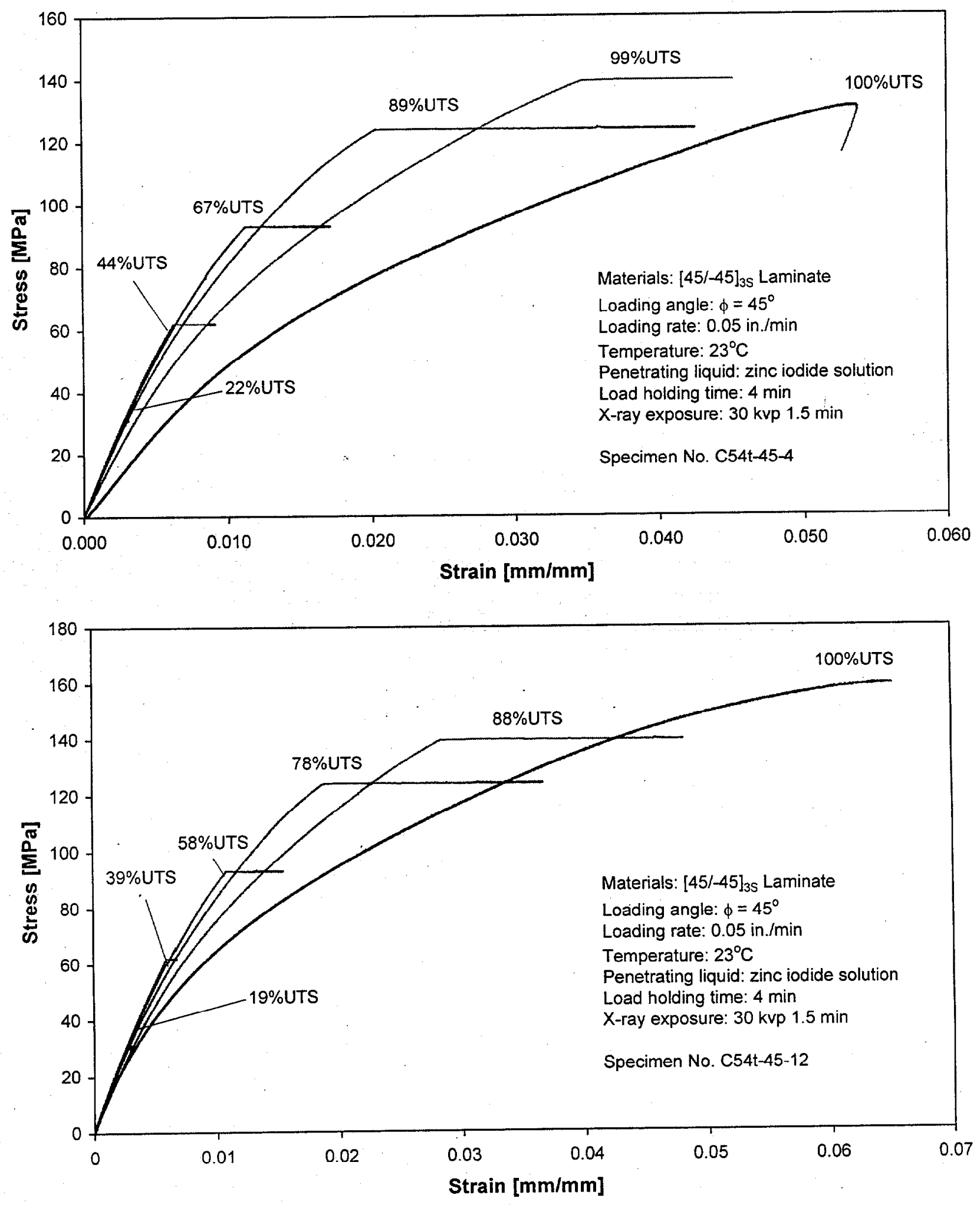

Fig. 19. Stress-strain curves of $[45 /-45]_{3 \mathrm{~S}}$ laminated coupon, at loading angle $\phi=45^{\circ}$, subjected to progressively stepped-up load levels. 


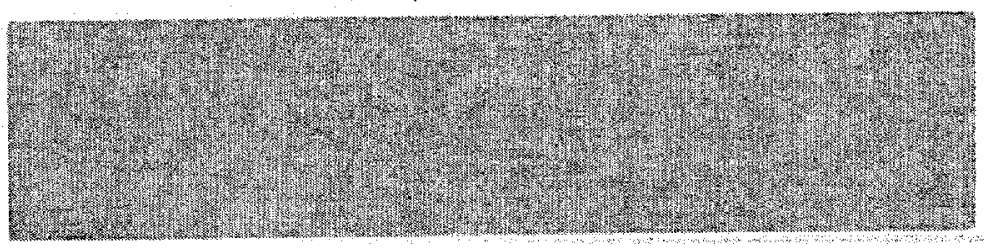

Virgin

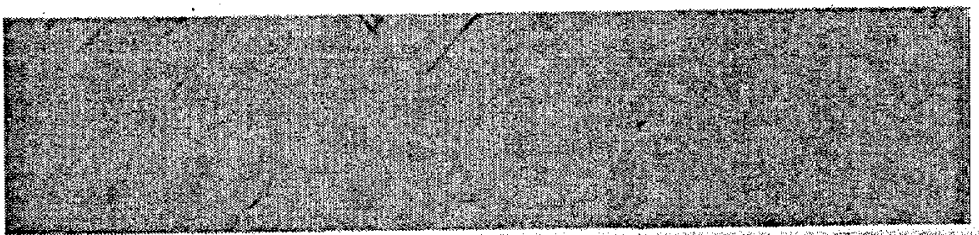

$22 \%$

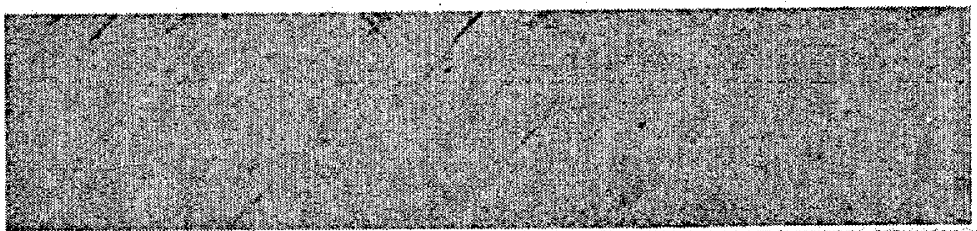

$44 \%$

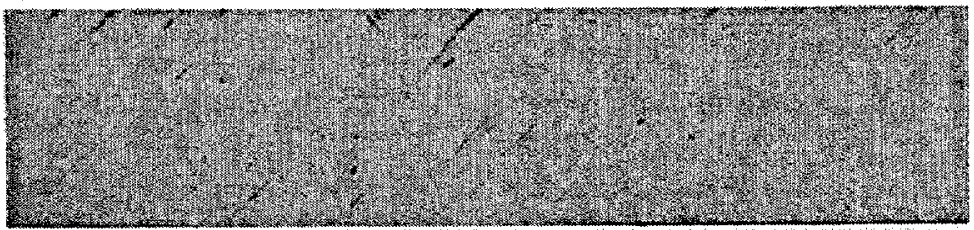

$67 \%$

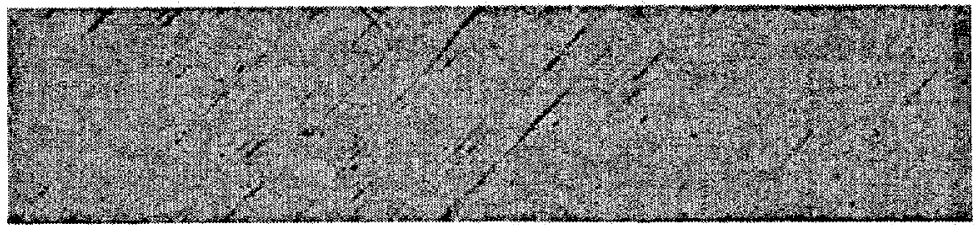

$89 \%$

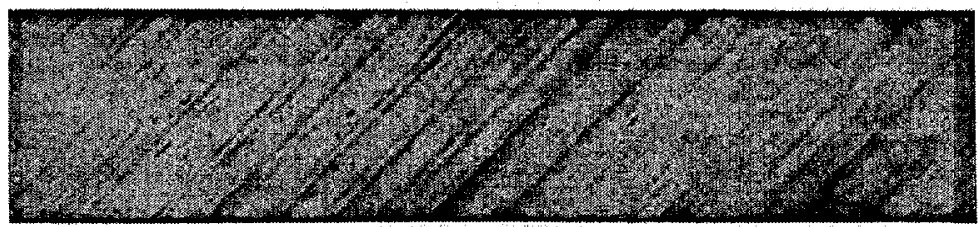

$95 \%$

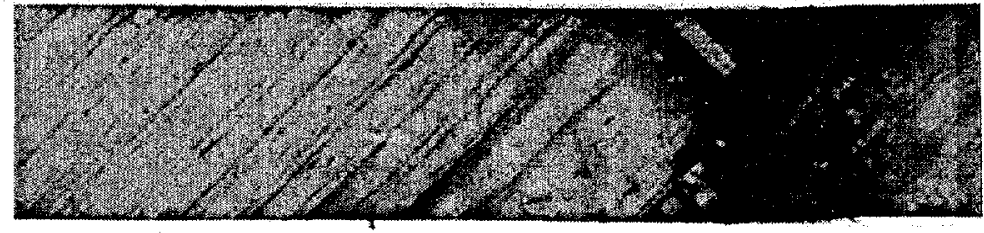

Failure

Specimen No. C54t-45-4

Fig. 20. (a) X-ray images showing damage in [45/-45] 3 stitched T300 mat/urethane 420 IMR composite $\left(\phi=45^{\circ}\right)$ at various stress levels (in \%UTS). 


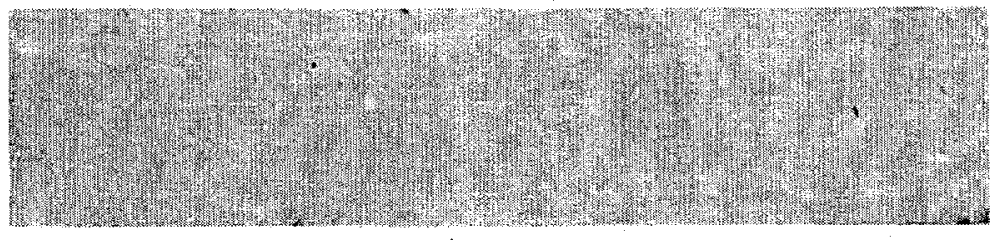

Virgin

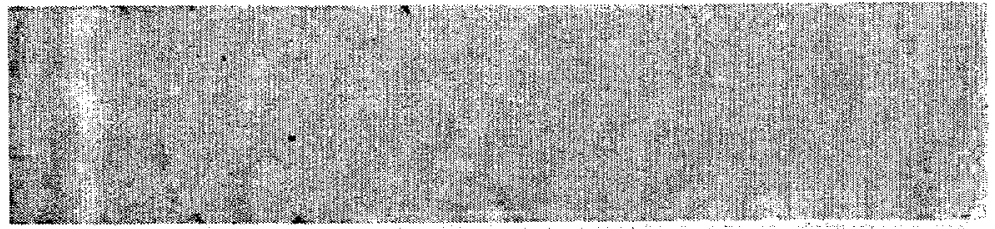

$19 \%$

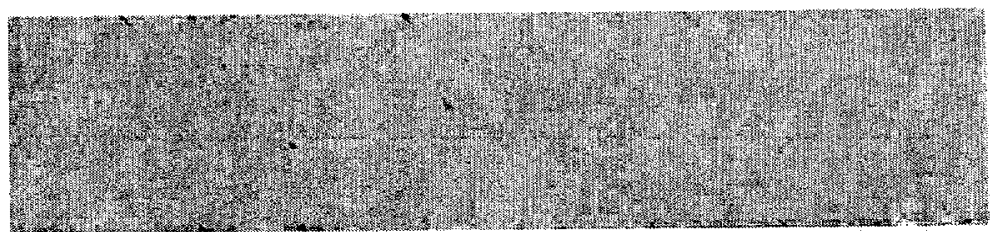

$39 \%$

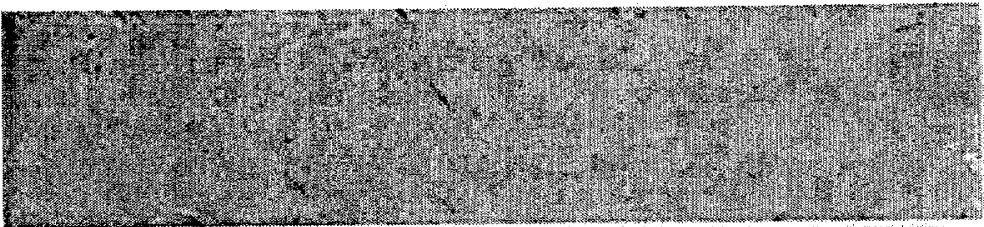

$58 \%$

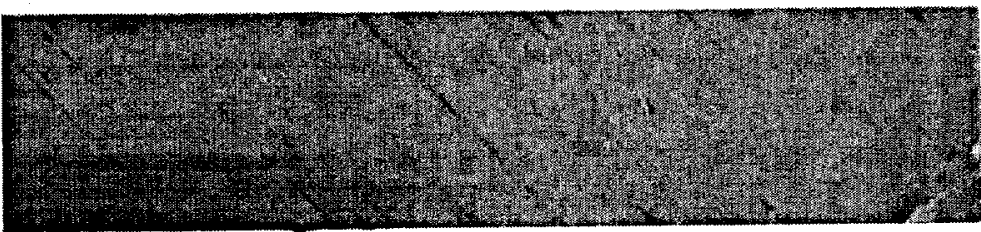

$78 \%$

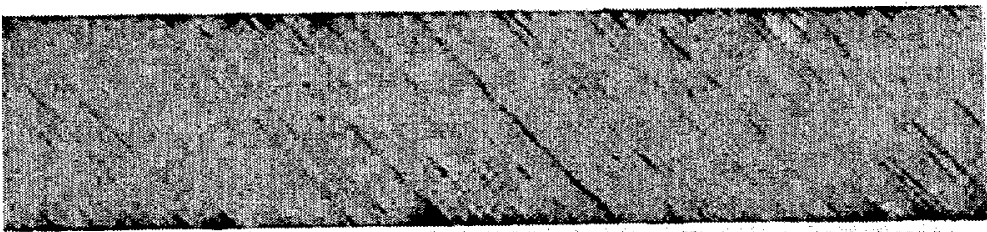

$88 \%$

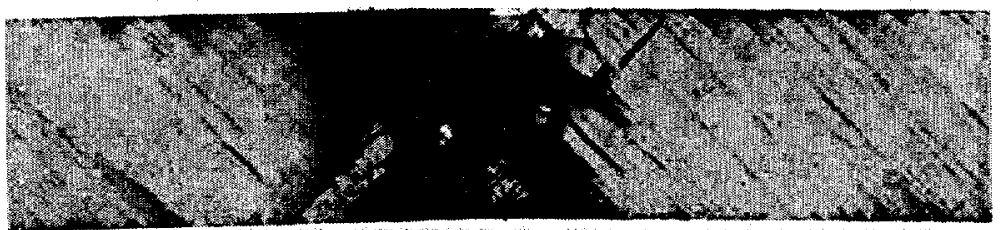

Failure

Specimen No. C54t-45-12

Fig. 20. (b) X-ray images showing damage in $[45 /-45]_{3 \mathrm{~S}}$ stitched T300 mat/urethane $420 \mathrm{IMR}$ composite $\left(\phi=45^{\circ}\right)$ at various stress levels (in \%UTS). 


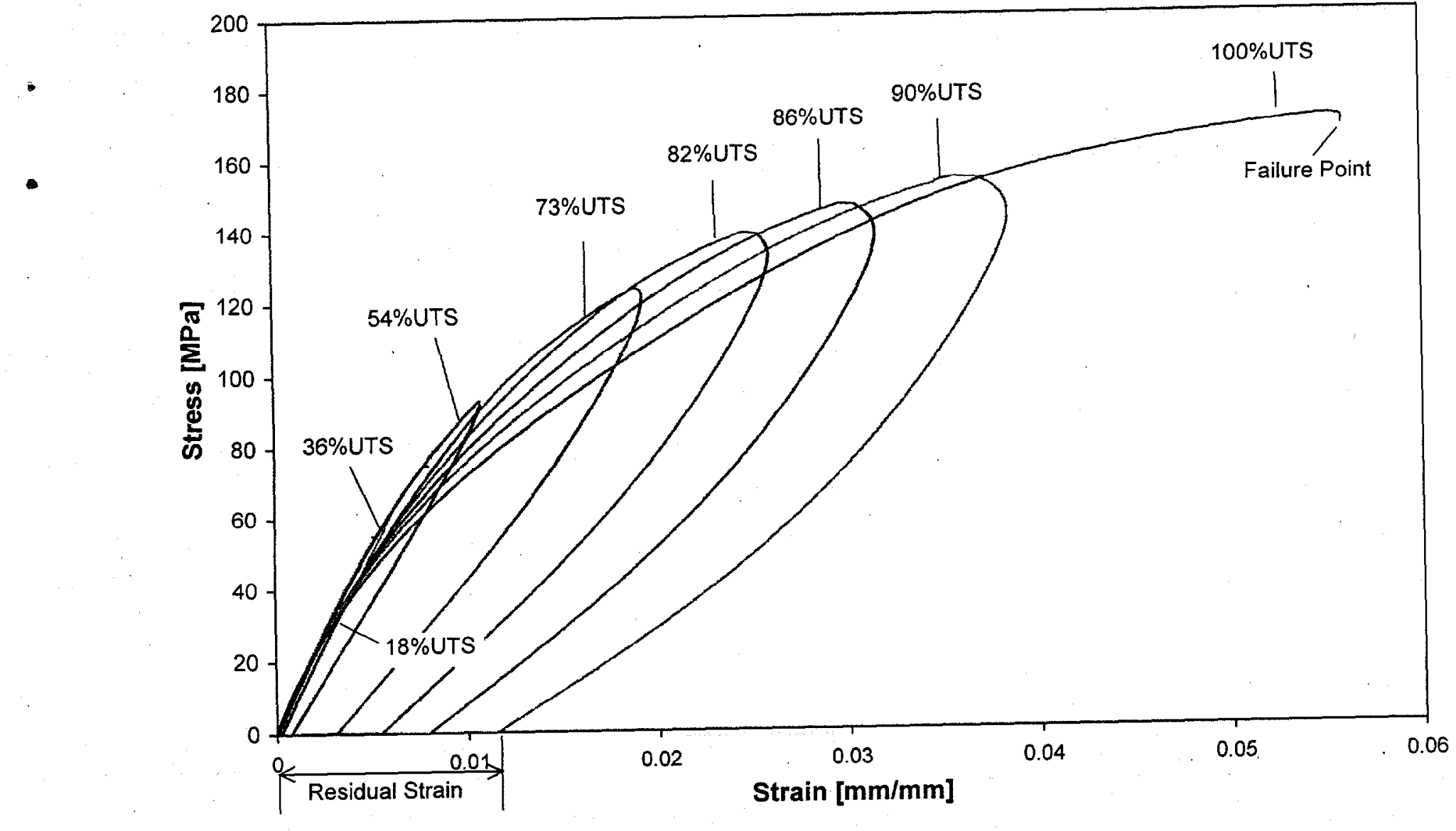

Fig. 21. Loading-unloading curves of a typical $[45 /-45]_{3 s}$ laminate coupon with $\phi=45^{\circ}$ showing the evolution of internal damage with increasing stress levels. 


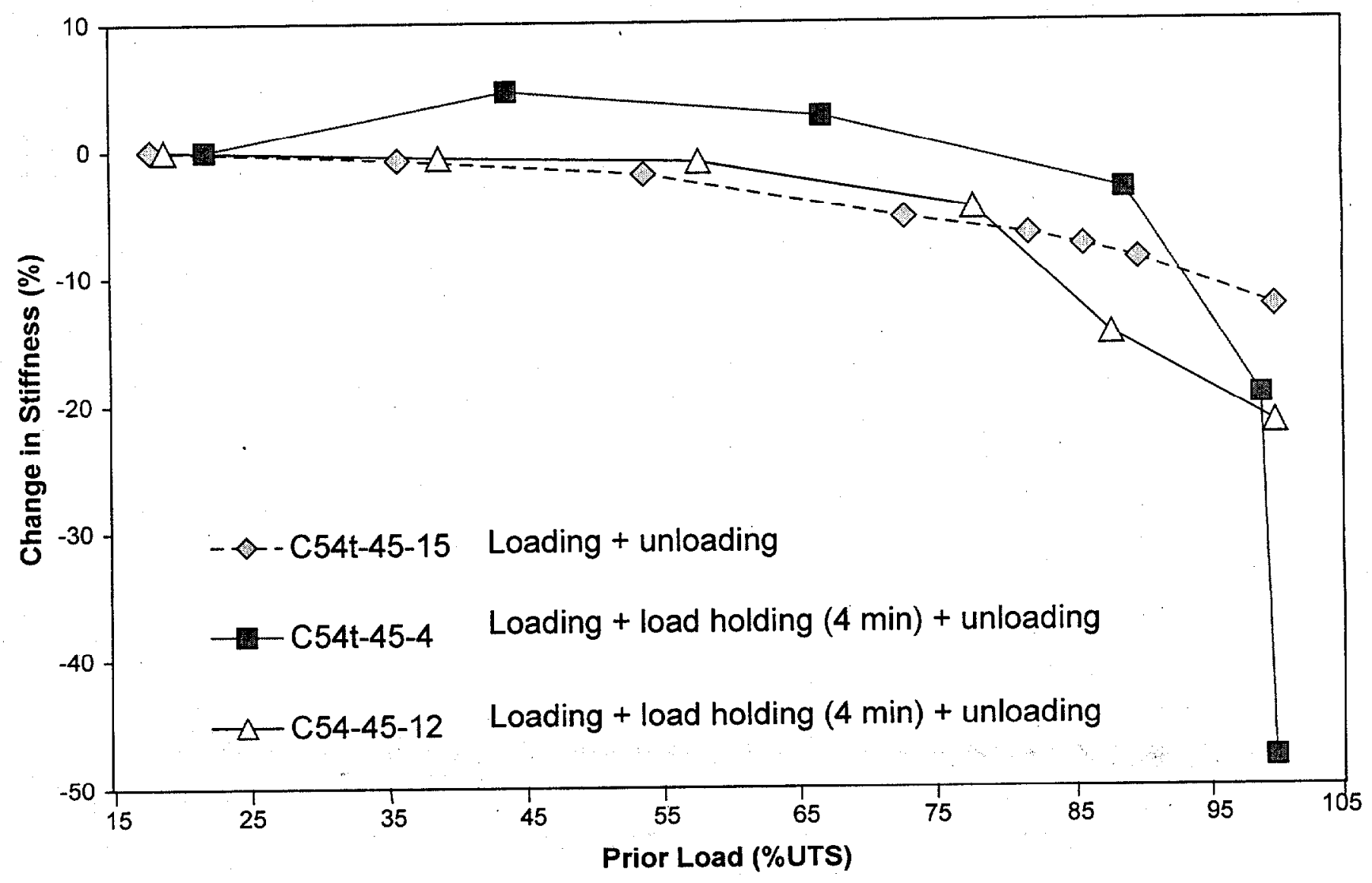

Fig. 22. Stiffness reduction of $[45 /-45]_{3 s}$ laminate coupons $\left(\phi=45^{\circ}\right)$, as recorded within the linear range, on reloading due to prior tensile loading. 


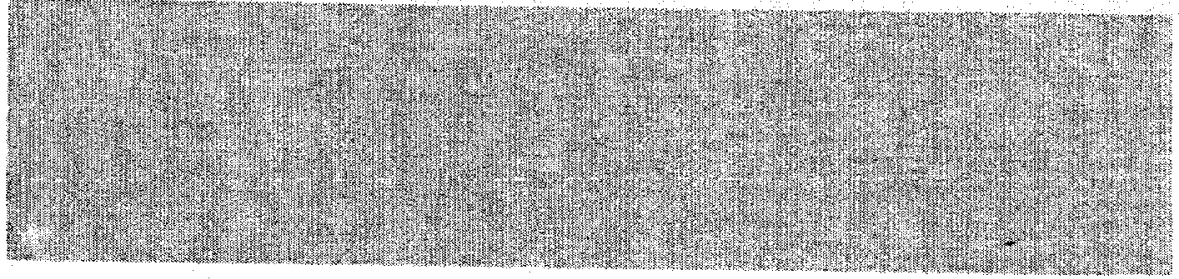

Virgin

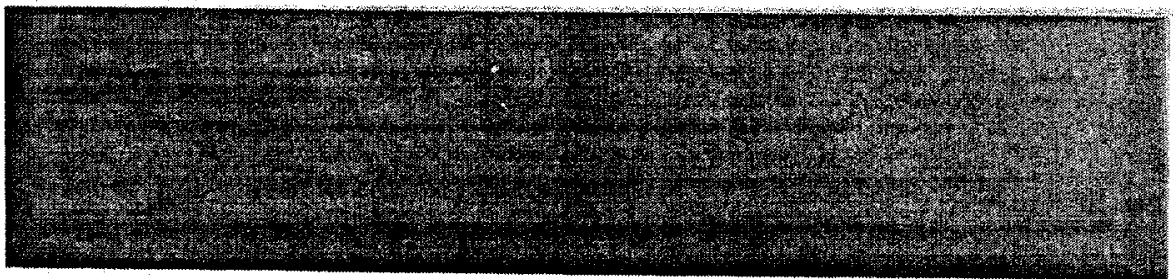

$60 \%$

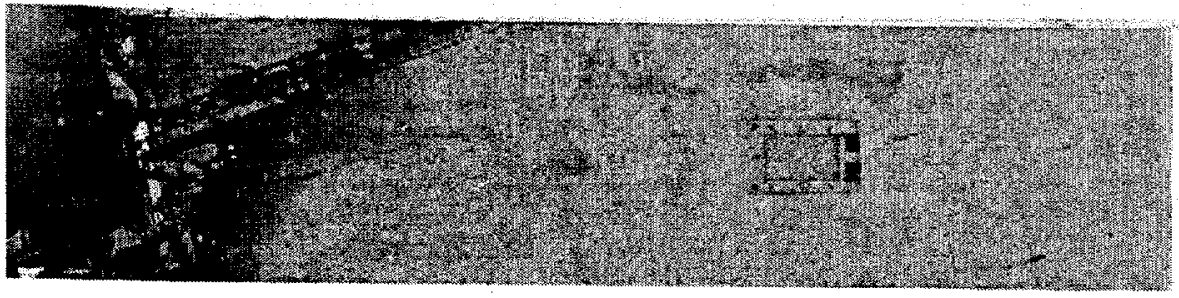

Failure

Fig. 23. X-ray images of a $[45 /-45]_{3 \text { s }}$ stitched T300 mat/urethane 420 IMR coupon $\left(\phi=15^{\circ}\right)$ subjected to various stress levels (in \%UTS). No extensive damage can be detected prior to final failure. 


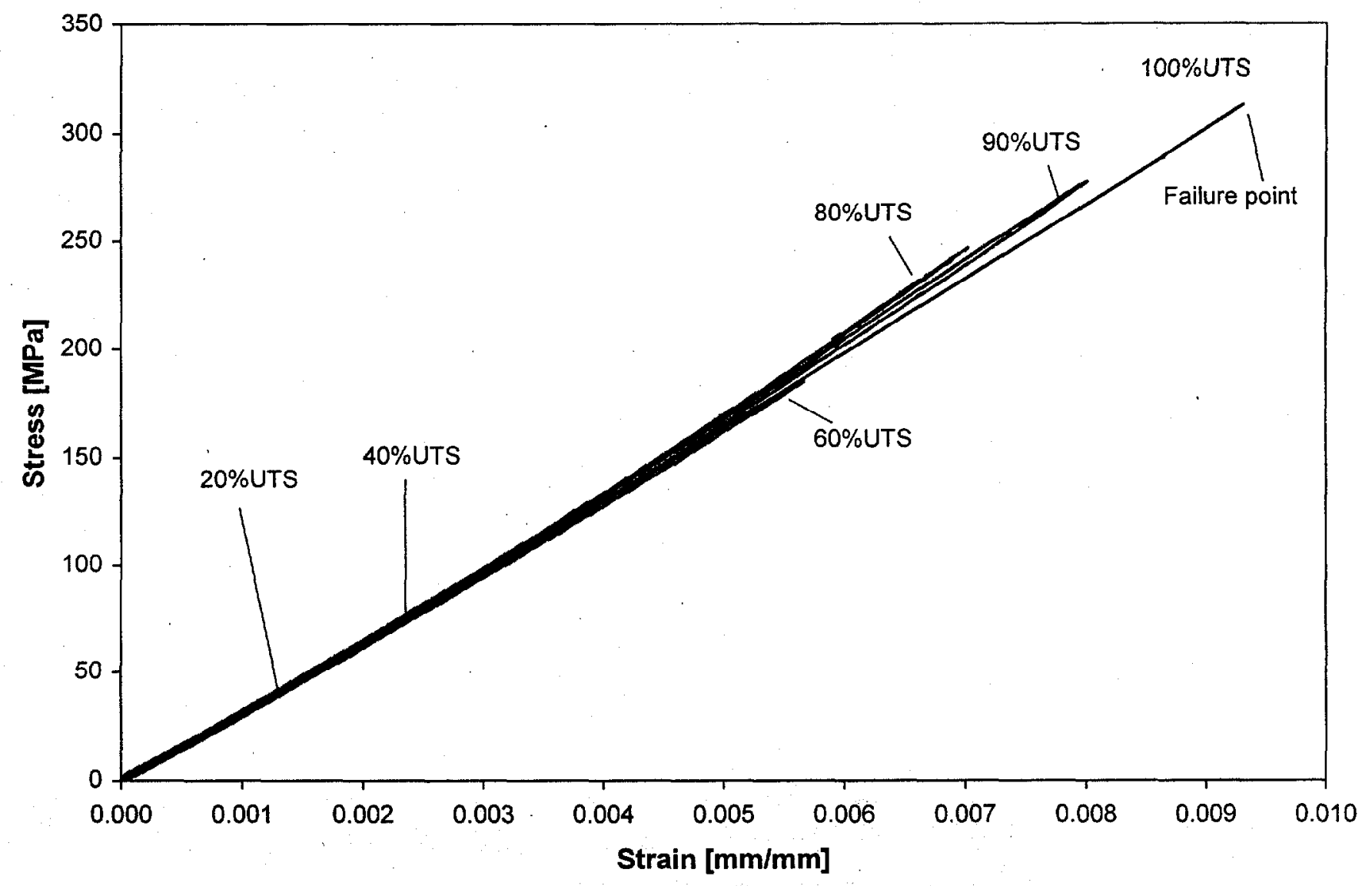

Fig. 24. Loading-unloading stress-strain curves of a quasi-isotropic coupon with different stress levels at a loading direction $\phi=45^{\circ}$ (specimen TJB59-45-1). 


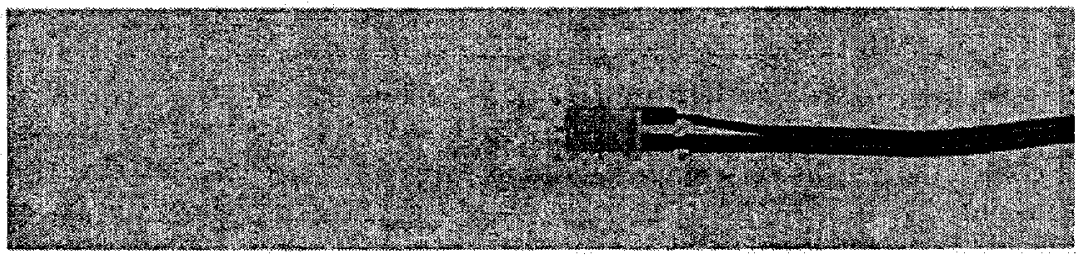

Virgin

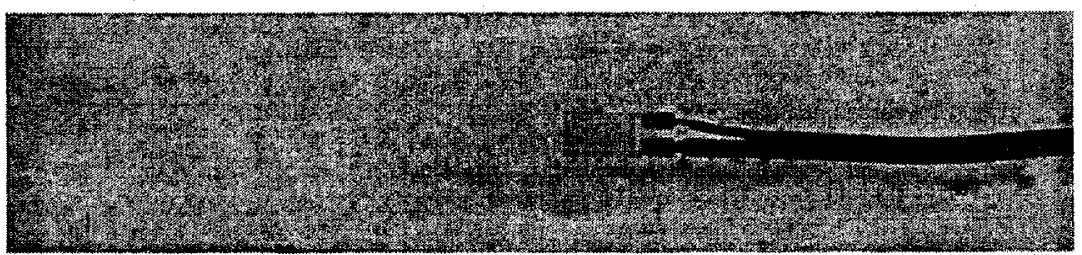

$60 \%$

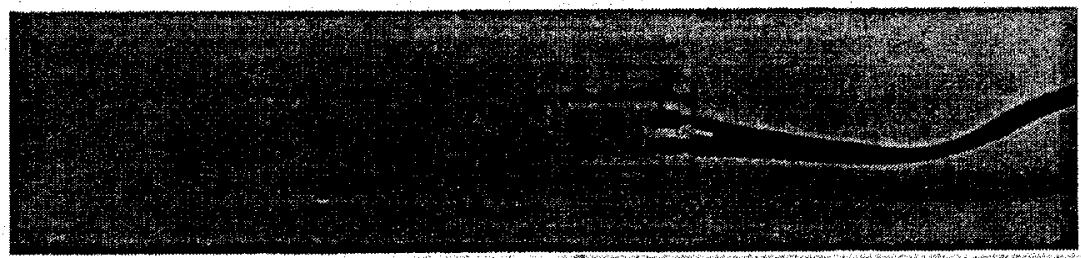

$90 \%$

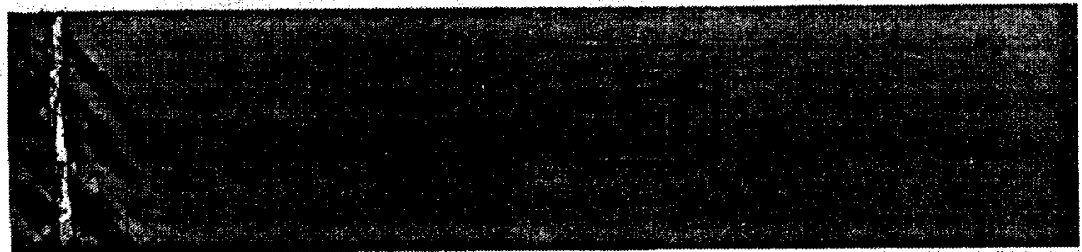

Failure

Fig. 25. X-ray images of a quasi-isotropic coupon subjected to various stress levels (in \%UTS) at a loading angle $\phi=45^{\circ}$. No extensive damage could be detected until the advent of final failure (specimen TJB59-45-1). 


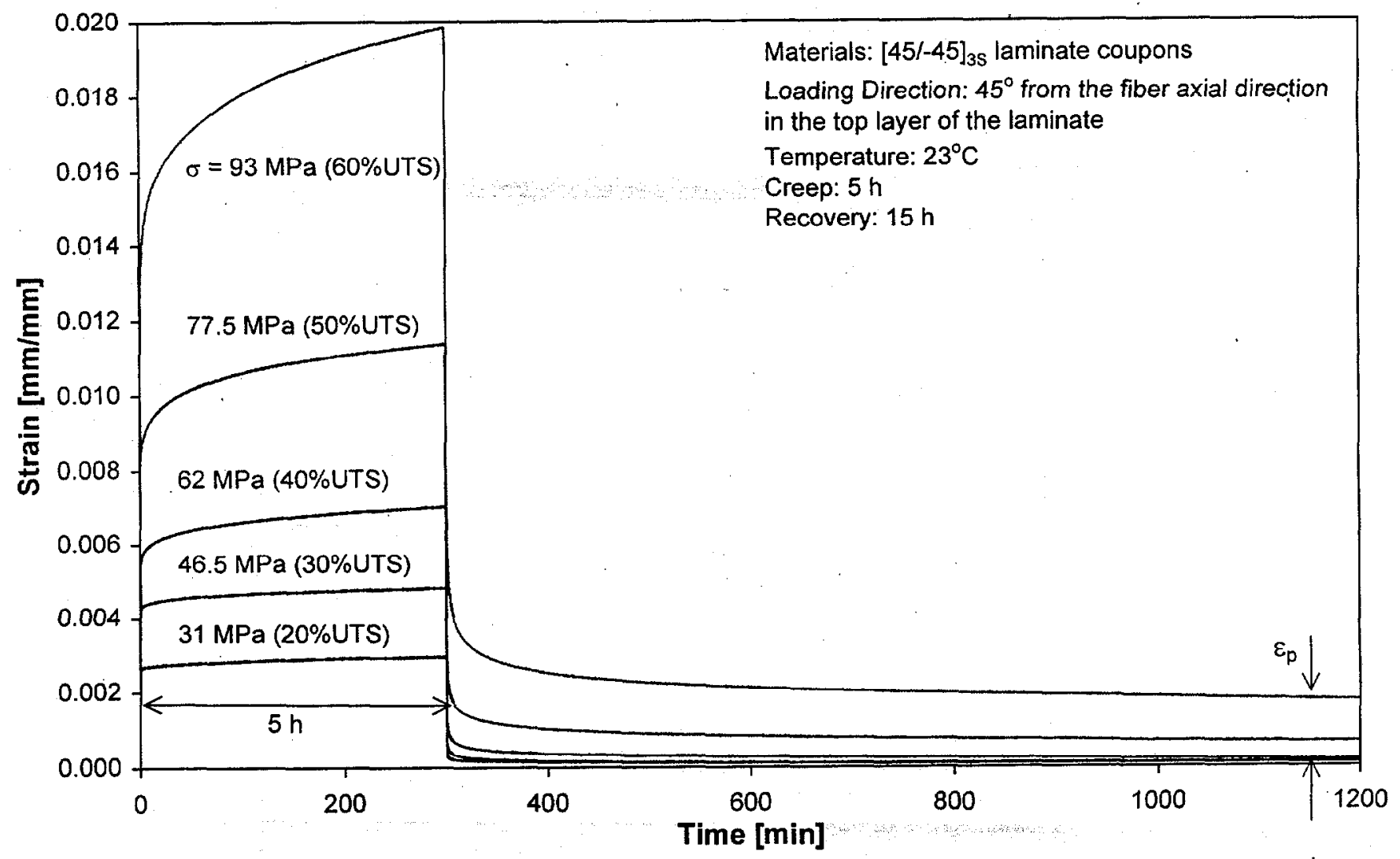

Fig. 26. Typical creep and recovery curves of $[45 /-45]_{3 s}$ laminate coupons $\left(\phi=45^{\circ}\right)$ at $23^{\circ} \mathrm{C}$ under various stress levels. 


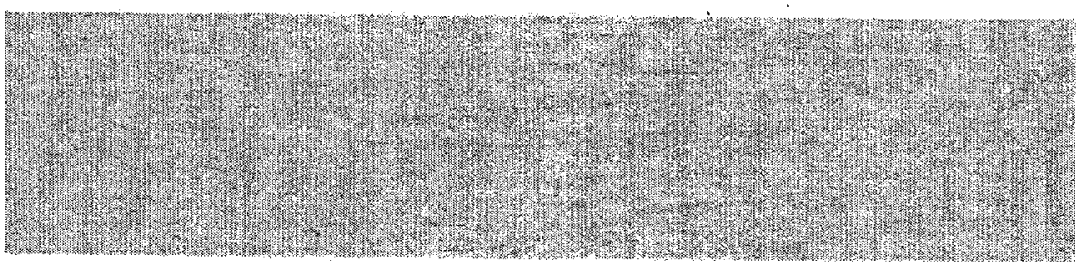

Virgin

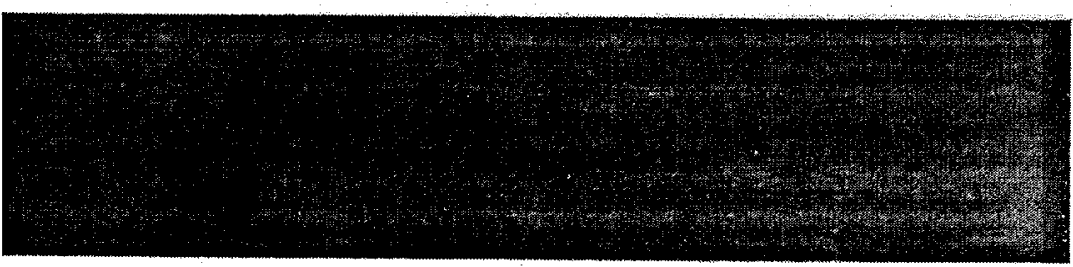

$60 \%$

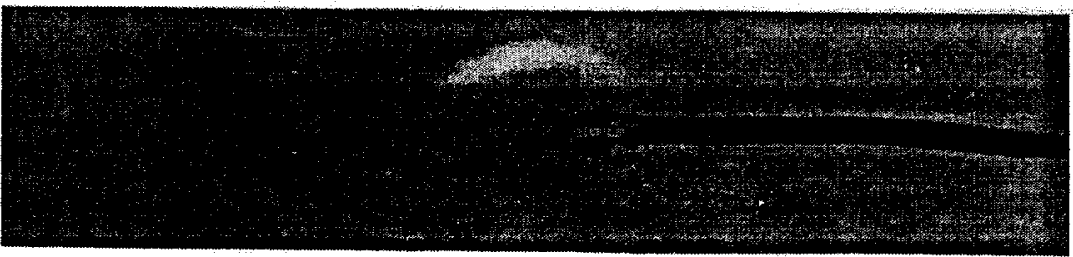

$70 \%$

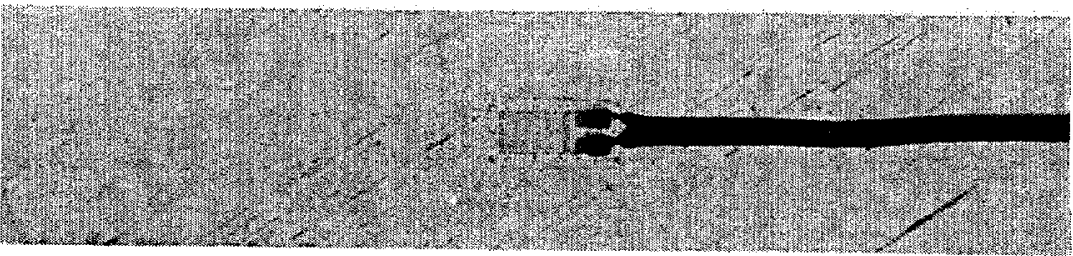

$80 \%$

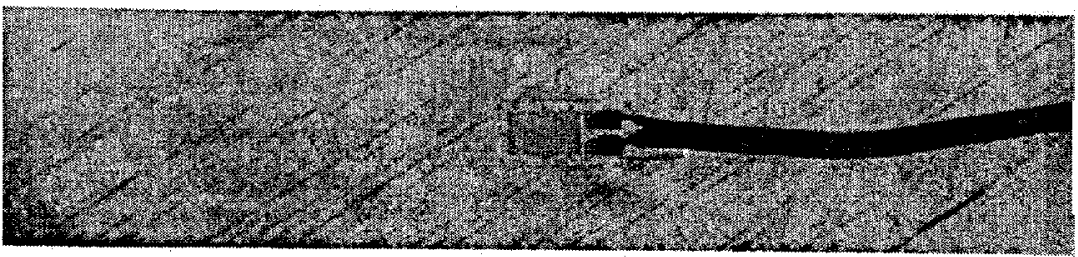

$90 \%$

Fig. 27. X-ray images showing damage after creep loading in $[45 /-45]_{3 \mathrm{~S}}$ stitched T300 mat/urethane 420 IMR composite $\left(\phi=30^{\circ}\right)$ at various stress levels (in \%UTS). 


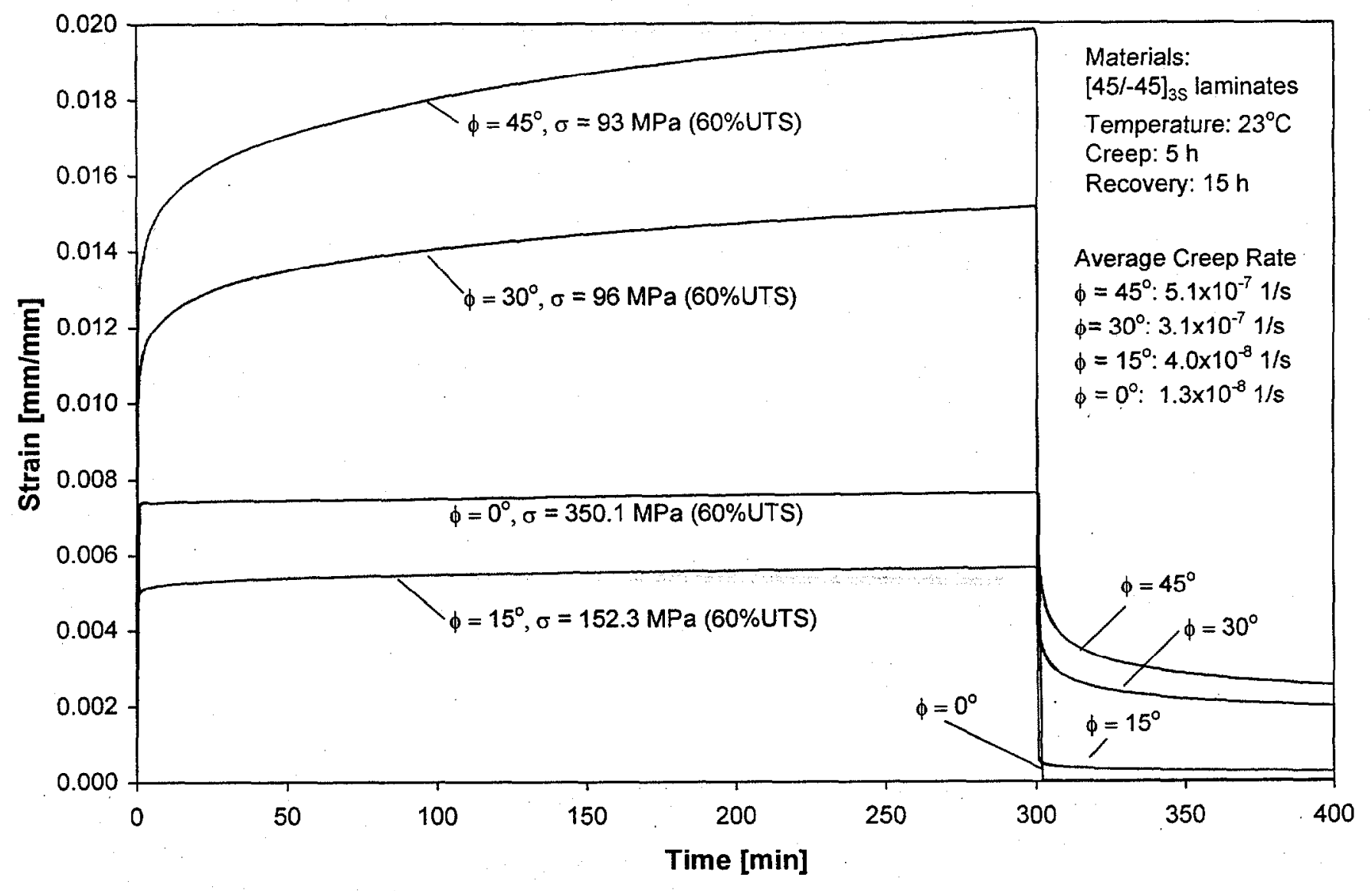

Fig. 28. Typical creep and recovery curves of $[45 /-45]_{3 s}$ laminate coupons $\left(\phi=0^{\circ}, 15^{\circ}, 30^{\circ}, 45^{\circ}\right)$ at $23^{\circ} \mathrm{C}$ under an applied creep stress $\sigma=60 \%$ UTS. 
ORNL/TM-2000/103

\section{INTERNAL DISTRIBUTION}

1. R. L. Battiste

2. R. G. Bowman

3. C. R. Brinkman

4-7. J. M. Corum

8. W. G. Craddick

9-11. S. Deng

12. D. L. Erdman

13. J. G. Hansen

14. L. D. Klett

15. R. E. Norris

16. M. B. Ruggles
17. J. M. Starbuck

18. P. A. Sklad

19. C. D. Warren

20-30. Y. J. Weitsman

31. G. T. Yahr

32. S. Simunovic

33. R. E. Ziegler

34. ORNL Patent Section

35. Laboratory Records, ORNL-RC

36-37. Laboratory Records, OSTI

\section{EXTERNAL DISTRIBUTION}

38. M. Elahi, 111-F Prosperity Ave., Leesburg, Virginia 20175.

39-67. E. M. Hagerman, Automotive Composite Consortium, General Motors, 30500 Mound Road, I-6, Box 9055, Warren, Michigan 48090-9055.

68. J. M. Henshaw, Department of Mechanical Engineering, The University of Tulsa, 600 S. College Avenue, Tulsa, Oklahoma 74104-3189.

69. G. A. Holmes, National Institute of Standards and Technology, Bldg. 224, Room B116, MS: Room B108, Gaithersburg, Maryland 20899.

70. K. Liechti, Engineering Mechanics Research Laboratory, Department of Aerospace Engineering and Engineering Mechanics, The University of Texas at Austin, Austin, Texas 78712.

71. D. Oplinger, AAR-431, FAA William J. Hughes Technical Center, Atlantic City International Airport, New Jersey 08405.

72. T. A. Reinhart, The University of Dayton Research Institute, 300 College Park Drive, Dayton, Ohio 45469-0130.

73. W. Ren, AFRL/MLLN, 2230 Tenth St., Bldg. 655, Rm. 23, WPAFB, OH 45433-7817.

74. R: A. Schapery, Engineering Mechanics Research Laboratory, Department of Aerospace Engineering and Engineering Mechanics, The University of Texas at Austin, Austin, Texas 78712.

75. C. R. Schultheisg, National Institute of Standards and Technology, Building 224, Room A209, Gaithersburg, Maryland 20899.

76. T. D. Seagrave, Bayer Corporation, 100 Bayer Road, Pittsburgh, Pennsylvania 15205.

77. L. V. Smith, Washington State University, School of Mechanics and Materials Engineering, Pullman, Washington 99164-2920.

78-81. J. A. Carpenter, U.S. Department of Energy, 1000 Independence Avenue, SW, Washington, DC 20588.

82. P. G. Patil, U.S. Department of Energy, 1000 Independence Avenue, SW, Washington, DC 20588 .

83. M. Rowlins, U.S. Department of Energy, Oak Ridge Site Office, Oak Ridge, Tennessee 37831. 
*

I

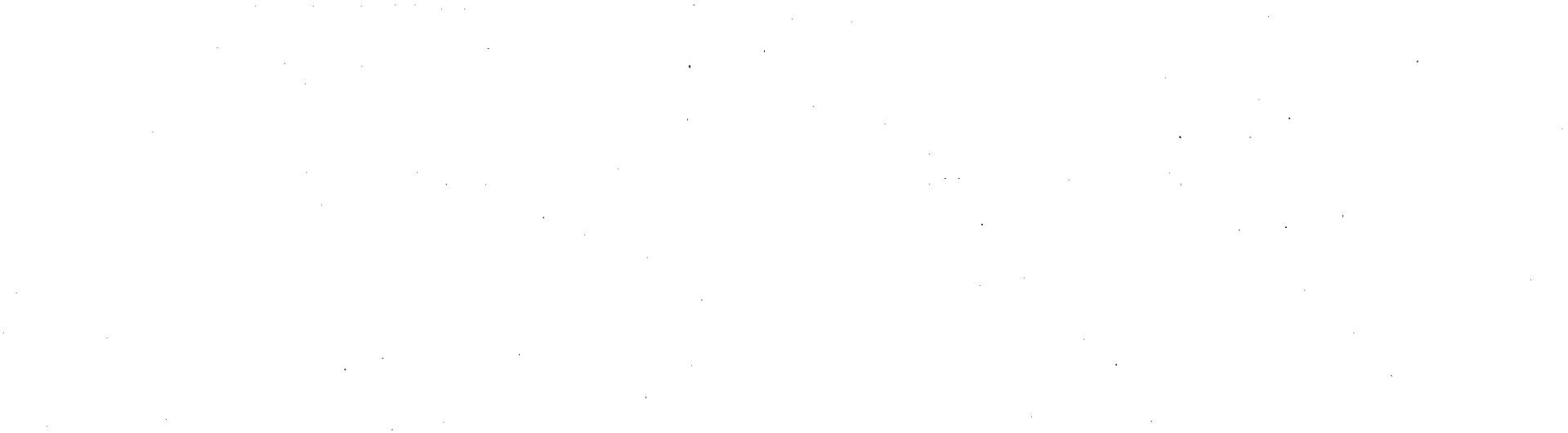

$=$ 